\title{
MEMORIA DE UN EPISODIO \\ EN LA HISTORIA \\ DE LA INVESTIGACIÓN SOCIAL*
}

\section{Paul F. Lazarsfeld}

Una autobiografía sólo merece escribirse cuando se da una de estas tres condiciones: cuando el autor es un hombre de grandes logros (Einstein, Churchill), cuando por su posición ha estado en contacto con acontecimientos o personas muy importantes (un corresponsal extranjero) o cuando, por circunstancias externas, puede ser considerado como un "caso" que representa una situación o un proceso de interés.

En este último sentido, las biografías (o historias de vidas) han sido una fuente para la investigación social. Situaciones críticas — como extrema pobreza, conflictos culturales y campos de concentración - han sido estudiadas a través de documentos personales. En general, están separados la fuente del material y el análisis de los que se intenta sacar conclusiones de ellos: el testigo y el experto representan diferentes papeles. Este ensayo representa un esfuerzo para combinar las dos funciones. Me defino a mí mismo como un testigo experto.

Pero ¿testigo de qué? Supongo que se me incluye en este volumen porque

* El texto original se titula "An Episode in the history of Social Research: A Memoir by Paul F. Lazarsfeld", publicado en el vol. II (1968) de Perspective in American History, pp. 270-337. También se publicó en D. Fleming y D. BAilyn, Intelectual Migration: Europe and America, 1930-1960 (Cambridge, Harvard University Press, 1969). La traducción se ha hecho del texto de 1968. 
he tenido actuaciones en estos dos procesos: la expansión de los Institutos de investigación social en las Universidades norteamericanas y el desarrollo de un estilo de investigación que prevalece en muchos de ellos. Estos dos elementos tienen sus raíces en mi previa experiencia europea. Mi labor en este trabajo consiste, pues, en analizar tan claramente como sea posible los escalones - los mecanismos psicológicos y sociales - que entraron en juego por la parte europea de mi biografía profesional, cuando me trasladé a este país, hace treinta y seis años.

El tema de este ensayo se puede presentar fácilmente. Cuando empezó mi carrera académica, las ciencias sociales en Europa estaban dominadas por mentes filosóficas y especulativas. Pero el interés por trabajos más concretos era visible — simbolizado, por ejemplo, por el hecho de que Ferdinand Tönnies, el presidente permanente de la Sociedad Alemana de Sociología, estableciese en esa organización una sección de sociografía- Sin ninguna adscripción formal, mis intereses investigativos se desarrollaron en esta dirección empírica. Al mismo tiempo, en los Estados Unidos, el conductivismo y el operativismo dominaban el ambiente intelectual; aquí también se palpaba que se empezaba a sentir un interés minoritario en esa dirección de la investigación empírica; por ejemplo, en la publicación por el Social Science Research Council (Consejo de Investigaciones Sociales Científicas) de una monografía sobre el uso de documentos personales, así como el interés profundo en las variables y actitudes intervinientes ${ }^{1}$.

En esta situación, me convertí en un elemento de conexión. Un "positivista» europeo era una curiosidad bienvenida por hombres conscientes de las tendencias sutiles en las ciencias sociales norteamericanas. Mientras en Europa el desarrollo de la ciencia social se paralizó con la llegada de Hitler, en América las tendencias evolutivas se ensancharon - es decir, se diversificaron y refinaron- y ello requería nuevas formas institucionales. Mis experiencias e intereses me han permitido desempeñar un papel en este desarrollo. Desde luego, muchas de las cosas que hice se hubieran hecho en cualquier otra parte. Sin embargo, el trasiego intelectual necesita portadores, y mi buena suerte consistió en que fui uno de ellos.

El presente ensayo intenta dar cuenta de mis experiencias mediante un procedimiento aplicable, creo, a cualquier material descriptivo, personal o colectivo. Si me viera forzado a dar un título a las páginas que siguen, las rotularía como contribución al estudio de la innovación en la educación superior. He incluido material documental que facilite al lector su propio juicio sobre ciertas cuestiones y le informe de las fuentes históricas disponibles. Al mismo tiempo, he intentado organizar esos materiales en torno a cierto número de ideas generales — constructos integrados - con la esperanza de que sean de

1 Gordon Allport, The Use of Personal Documents in Psychological Science (Nueva York, 1942; Louis GotTschalk, Clyde KluCKhohn y Robert Angell, The Use of Personal Documents in History, Anthropology and Sociology (Nueva York, 1945). 
interés para los estudiosos de la innovación. Ello me dispensa del problema de tener que resaltar el mérito de la innovación, y gravita sobre el modo del análisis.

En ocasión reciente he urgido a mis colegas a que estudien el trabajo de los científicos sociales desde el punto de vista de «las decisiones que subyacen al producto final; no hay ninguna razón para que esta exégesis no pudiera ser escrita por los mismos autores. Nos desinteresamos demasiado de las autobiografías de los intelectuales» ${ }^{2}$. Estoy en deuda con los editores de este volumen por proporcionarme la oportunidad de poderlo hacer.

\section{CALENDARIO DE HECHOS EXTERNOS}

En el carácter general de la vida de Viena después de la primera guerra mundial hay tres elementos que han sido decisivos para el relato que sigue: el ambiente político, el interés por lo que entonces se llamó "psicología», y el sentido de responsabilidad con lo que hoy se describe como esfuerzos para la «explicación».

Fui un miembro activo del movimiento estudiantil socialista, que estaba cada vez más a la defensiva ante la ola creciente del nacionalismo. Nos preocupaba que nuestra propaganda no tuviera éxito, y pedimos a los estudios de psicología conductista que lo explicasen. Recuerdo la fórmula que ideé en esa época: una revolución en lucha requiere economía (Marx); una revolución victoriosa requiere ingenieros (Rusia); una revolución fracasada reclama psicología (Viena).

No se enseñaba Sociología en la Universidad, excepto en algunas lecciones del filósofo social Othman Spann ${ }^{3}$. Mi grupo social de referencia fue el movimiento en torno a Alfred Adler, cuya oposición a Freud tenía un fuerte tinte sociológico. Tuvo muchos seguidores entre los profesores, e influyó en la reforma educativa patrocinada por la municipalidad socialista de Viena.

La educación, en un sentido amplio, era una gran preocupación de responsabilidad. Como alumno de escuela — antes de entrar en la Universidad a los dieciocho años - trataba entre mis compañeros de combinar las ideas del movimiento juvenil germano con la propaganda socialista ${ }^{4}$. Una vez estudiante continué con las reglas de los años anteriores: ahora era "demasiado mayor» para ser un revolté y, por eso, me convertí en un «educador» amateur. Ejercí como consejero en campos infantiles socialistas y como tutor en escuelas de

2 «Problems in Methodology», en el vol. de Robert K. Merton, Leonard Broom y Leonard S. Contrell (eds)., Sociology Today (Nueva York, 1959), p. 78.

${ }^{3}$ Hubo una rama vienesa de la Sociedad Sociológica Alemana, pero hasta donde recuerdo no tuve ningún contacto con ella. Más tarde encontré a algunos de sus miembros mencionados como participantes en los debates impresos del anuario alemán Soziollogentag.

${ }^{4}$ Uno de los raros informes en inglés sobre el movimiento juvenil de ese período es el de Walter LaQUeur, Young Germany: History of the German Youth Movement (Nueva York, 1962). 
segunda enseñanza para jóvenes de clase obrera. Todo eso fue parte de mi esfuerzo para promover el espíritu del socialismo 5 .

La principal influencia intelectual procedía de un grupo de escritores famosos sobre ciencia y filosofía de la ciencia: Ernst Mach, Henri Poincaré y Einstein. Me impresionó la idea de que la mera "clarificación" suponía un camino para descubrir. El teorema de Euclides sobre las paralelas no era verdad, sino un axioma. No tiene sentido decir que un acontecimiento en la luna y otro en la tierra ocurrieron simultáneamente. Todas las ideas que más tarde se conocieron como "explanaciones» produjeron una gran fascinación en mí, y este interés con frecuencia se confunde con la convicción de que «saber cómo las cosas se han hecho" es una meta educativa muy prioritaria. Cuando, siendo estudiante, trabajaba en el campo de la educación obrera, enseñé muchas veces "cómo leer un periódico": ¿qué es una agencia de noticias, cómo hay que tener en cuenta las fuentes de las noticias, qué debe uno observar en diferentes países? Uno de los principales colaboradores de Adler publicó una serie de pequeños panfletos aplicando sus ideas a varios problemas sustantivos; yo escribí mi colaboración con el título "Detrás de las paredes de la escuela». La idea principal era que se podía evitar mucha ansiedad si las familias entienden cómo se organizan las escuelas, cómo se dan las calificaciones, cómo los maestros difieren entre sí en sus percepciones de los estudiantes, etc. ${ }^{6}$. En esa época no tenía ningún contacto con el "Círculo de Viena», aunque sus principales figuras ya estaban establecidas en Viena. La obvia similitud de lo que acabo de describir con sus enseñanzas es probablemente algo que tiene más que ver con una situación común que con una influencia directa.

Ir a la Universidad fue algo ya dado por sabido en una familia de clase media, incluso en una de medios limitados. El campo natural de estudio para alguien que participaba activamente en la vida política era un doctorado en Staatswissenschaft, un título modificado de Derecho con un fuerte componente de Economía y Teoría política. Pero para mí la matemática constituyó un segundo centro de atracción, y durante varios años seguí los cursos de ambos campos. Fue casi accidental que acabase con un doctorado en matemáticas aplicadas. Inmediatamente después de obtener el grado empecé a enseñar matemática y física en un Gymnasium.

Cuando todavía era un estudiante, mi interés en la ciencia social tomó un nuevo giro con la llegada de dos famosos psicólogos a la Universidad de Viena. No hubo psicología real hasta que llegaron Charlotte y Karl Bühler en 1923 para constituir un nuevo Departamento. Karl Bühler era una figura académica

5 Mi primera publicación, a la edad de veintitrés años (Gemeinschaftziefserdurch Ezzihungsggemeinschaften Viena, 1929), fue un informe sobre un campo, que organicé junto a mi amigo Ludwig Wagner, para el desarrollo de un espíritu socialista en gente joven.

6 Paul F. Lazarsfeld, «Hinter den Kulissen der Schule», en Sofie Lazarsfeld (ed.), Technik der Erziehung (Leipzig, 1929). Cualquiera que haya leído la introducción al vol. de Paul F. Lazarsfeld y Morris S. Rosemberg (eds.), The Language of Social Research (Nueva York, 1955) verá la extensión de esas inclinaciones intelectuales que han permanecido durante treinta años. 
importante que, siendo más joven, había contribuido a una revolución de mucho calado en psicología experimental con su trabajo sobre psicología del acto de pensar. Su esposa, Charlotte, bastante más joven que él, fue nombrada profesora asociada, y fue, de hecho, la administradora del Departamento. (Utilizaré el término europeo correcto: Instituto.) Participé en sus primeros seminarios, y un poco más tarde me pidieron que ofreciera un curso de Estadística.

Mi trabajo como asistente en la Universidad se fue ampliando poco a poco, y también enseñé psicología social y aplicada. Recibía una pequeña remuneración, en modo alguno suficiente para dejar mi puesto en el Gymnasium. Entretanto, mi deseo de entrar en el Instituto de Psicología creció enormemente, y en torno a 1927 tuve la idea de que yo crearía una sección de psicología social en el Instituto. Esto me permitiría trabajar con contratos remunerados, y con esos ingresos obtendría un salario pequeño pero adecuado, permaneciendo en un nivel de vida generalmente bajo. La idea se realizó en forma de un Centro de Investigación independiente (Wirtschaftspspychologische Forschungsstelle), nombre que connota ampliamente la aplicación de la psicología a los problemas económicos y sociales, del cual Karl Bühler era el presidente. A partir de ahí dirigí los estudios aplicados de ese Centro, y al mismo tiempo di mis clases en el Instituto de la Universidad y supervisé trabajos de investigación. Un cierto número de estudiantes trabajaron en el Centro de Investigación, y sólo unos pocos trabajos se basaron en datos recogidos allí mismo ${ }^{7}$.

Charlotte Bühler dividió su trabajo en psicología infantil y adolescente. Mis actividades estaban estrechamente relacionadas con las de ella en este último campo. Ella organizó una serie de monografías sobre psicología de los adolescentes, y a mí se me encomendó escribir una sobre trabajo y juventud. El volumen, Jungen und Beruf, apareció en 1931; contenía algunos trabajos de otros miembros del Instituto, así como los míos. Una gran parte del libro se dedicó a una monografía de noventa páginas en la cual yo resumí toda la literatura entonces disponible sobre gente joven y sus aspiraciones laborales. Al mismo tiempo, publiqué trabajos sobre temas estadísticos y —en varias revistas del partido socialista- sobre Sociología política e industrial. Mis lecciones de estadística se publicaron como Manual para profesores y psicólogos. Se trató del primer libro de texto europeo sobre

Mi posición como asistente (o ayudante) en el Instituto de Psicología era más bien inconcreta e insegura. Como salvaguardia contra un posible cese mantuve mi posición en el sistema de la escuela secundaria mediante un prolongado permiso de ausencia.

Entre nuestros clientes estaba el Frankfurt Institut für Sozial Forschung. Su director, Max Horkheimer, había concebido una serie de indagaciones que finalmente aparecieron en Autorität und Familie. Uno de los estudios de Erich Fromm solicitó que se administraran los cuestionarios por trabajadores jóvenes, y se nos pidió a nosotros que organizásemos la parte del trabajo de campo que había que hacer en Austria. No me encontré con ninguno de los miembros del grupo de Horkheimer mientras estuve en Europa, pero tuve buen conocimiento de ellos cuando vine a los Estados Unidos. De hecho, en los Estados Unidos en 1934 trabajé con Fromm en el análisis del cuestionario que habíamos emprendido en Austria. 
estadísticas educativas, y fue ampliamente utilizado en diversas Universidades $^{8}$.

Hacia 1930 comencé a organizar un estudio de Marienthal, una aldea al sur de Viena, cuya población estaba casi toda ella desempleada'. Mis dos colaboradores principales fueron Hans Zeisel, ahora profesor en la Universidad de Chicago, y Marie Jahoda, ahora profesora en la Universidad de Sussex, en Inglaterra. (Esta última después realizó informes sobre juventud desempleada para la Liga de Naciones y la Oficina Internacional del Trabajo.) La investigación de Marienthal despertó el interés del representante en París de la Fundación Rockefeller, y en 1932 obtuve una beca de viaje a los Estados Unidos, adonde llegué en septiembre de $1933^{10}$.

Durante el primer año de mi beca en América, participé en diversos estudios, y visité los escasos Centros universitarios en que se enseñaba investigación social. En febrero de 1934, el partido conservador de Austria abolió la Constitución, declaró fuera de la ley al partido socialista y estableció un fascismo de tipo italiano. Mi posición en el sistema de la enseñanza secundaria fue cancelada y muchos miembros de mi familia fueron encarcelados, pero mi salario como asistente en la Universidad nominalmente no se vio afectado. Todo esto despertó la simpatía de los representantes de la Fundación Rockefeller y sirvió de pretexto para ampliar mi beca otro año más, nominalmente obedeciendo a la regla de que era necesario para un becario tener una posición segura a la que retornar.

Al finalizar mi período de becario, en el otoño de 1935, decidí permanecer en este país. Con la ayuda de Robert Lynd, profesor de Sociología en la Universidad de Columbia, obtuve un puesto en Nueva Jersey como supervisor del descanso laboral de los estudiantes, para la Administración Nacional de la Juventud, cuyas oficinas principales estaban en la Universidad de Newark. En el otoño de 1936 se estableció un Centro de Investigación en esa Universidad,

${ }^{8}$ Jungen und Beruf (Jena, 1931); Statistisches Praktihum für Psychologen uns Lehrer (Jena, 1929), Después, en este país, he trabajado y publicado en el campo de la Sociología matemática. Pero esto nunca ha sido una parte integrante de lo que se ha llamado la tradición de investigación de Viena-Columbia. No me referiré a ello, pues, en este ensayo.

9 Marie Jahoda, Paul F. Lazarsfeld y Hans Zeisel, Die Arbeitslosen von Marienthal (Leipzig, 1932; 2. ${ }^{a}$ edición, Frankfurt, 1961). Como parte de las actividades de mi nuevo Centro de Investigación en Viena, quise hacer un tipo de encuesta social para equilibrar sus actividades de investigación de mercados. Por razones que no puedo recordar, estaba interesado en hacer un estudio sobre el tiempo de ocio, y lo discutí con el líder del partido socialista, Otto Bauer. Éste consideró que era tonto estudiar los problemas de tiempo de ocio en una época de grave desempleo, y fue él quien sugirió un tema nuevo, al que me referiré repetidamente en este capítulo.

${ }^{10} \mathrm{El}$ modo en que recibí mi beca tiene su propio interés. El representante de la Rockefeller me dio un modelo de solicitud. Viviendo en el ambiente pesimista de Viena en esa época, estaba seguro de que no iba a obtener la beca, y no la solicité. En noviembre de 1932 recibí un cablegrama desde el Centro de París de la Rockefeller informándome de que mi solicitud se había extraviado y que querían otra solicitud. Ellos habían decidido, obviamente, darme la beca por la recomendación de su representante, y éste nunca pensó que yo no había presentado la solicitud. Envié por correo un «duplicado», y obtuve la beca. 
conmigo como director. Este Centro siguió la pauta de las líneas de su predecesor en Viena, y de ello hablaremos después.

En 1937, la Fundación Rockefeller inició en la Universidad de Princeton un importante proyecto de investigación sobre los efectos de la radio en la sociedad norteamericana. Fui designado como director de esta nueva "Oficina de investigación de la radio", que, en 1939, se transfirió a la Universidad de Columbia. Durante unos años fui profesor allí, y en 1940 accedí al puesto de miembro permanente del Departamento de Sociología como profesor asociado. La Oficina de investigación de la radio, más tarde transformada en Bureau of Applied Social Research, tuvo una existencia débil en sus comienzos, pero en 1945 se incorporó a la estructura de la Universidad. Desde entonces he permanecido en la Universidad de Columbia, trabajando en el Bureau y en el Departamento de Sociología.

\section{UN ESTILO DE INVESTIGACIÓN Y SUS POSIBLES RAÍCES}

Para describir el origen del nuevo estilo de investigación utilizaré dos fuentes: las publicaciones que aparecieron en alemán mientras estaba en Austria y los trabajos que escribí inmediatamente después de mi venida a Estados Unidos, para informar sobre el trabajo vienés a un nuevo auditorio. En cierto modo, me extiendo en este último trabajo aquí, acompañándolo de una interpretación adicional. Organizo mis actividades en torno a tres factores que me parecen significativos: un componente ideológico, un ambiente intelectual y ciertas características personales.

1. El componente ideológico. La motivación política se hace más aparente al subrayar la estratificación social que permeabilizaba las principales publicaciones austríacas. Jungen und Beruf señalaba que la literatura entonces floreciente sobre psicología de la adolescencia realmente trataba sólo de los adolescentes de clase media; era necesario llamar aparte la atención que merecían los problemas de los jóvenes de la clase obrera, que en aquella época empezaban a trabajar a los catorce años. Toda la monografía se organizaba en torno a una clara separación entre los dos grupos ${ }^{11}$.

El debate sobre una «juventud proletaria» estaba entrelazado con una interpretación psico-sociológica de la noción de «explotación». Teníamos la idea de que los jóvenes de la clase trabajadora, al entrar a trabajar a la edad de catorce años, se veían privados de la experiencia visible de los adolescentes de clase media. Por esta razón, el hombre de clase trabajadora nunca desarrollaba completamente una dimensión afectiva y, en consecuencia, permanecía en una

11 Un resumen del libro en inglés se publicará pronto por la Random House; su influencia política se presentará en la introducción. Es difícil darse cuenta hoy de la desatención hacia la noción de estratificación social en esa época. 
posición inferior. Este tema reapareció en el estudio de Marienthal: el efecto del desempleo reducía la "dimensión afectiva" de los hombres de la clase trabajadora. El trabajo frecuentemente citado de Genevieve Knupfer, «Retrato de un perro inferior ${ }^{12}$, procede de una tesis doctoral de Columbia, de 1947 , que fue el primer trabajo que reunió los datos de la estratificación a partir de encuestas de opinión pública. El dato a destacar lo constituyó el bajo nivel de aspiraciones y el estrecho «espacio vital» que prevalecía en los grupos de renta baja $^{13}$. La línea argumental era prácticamente idéntica a la que forma ahora la base ideológica de la "Movilización de la juventud», de Nueva York. Y se puede hacer una comparación entre mi libro primero y la contribución de Gans en el reciente volumen Uses of Sociology ${ }^{14}$, aunque estoy seguro de que no existe ninguna continuidad directa. Una diferencia importante es que Gans destaca una acción comunitaria, mientras en el caso original lo que se destaca es el retraso en el comienzo del trabajo manual y los cambios en el sistema educativo.

Este interés en la estratificación y en la significación social de la adolescencia de la clase trabajadora tenía un visible tinte marxista. El otro rasgo de esta influencia no es tan explícito, pero puede ser fácilmente documentado. En Jungen und Beruf había un orgullo especial en poner de manifiesto el efecto de los factores objetivos sobre las reacciones individuales. Varias tablas indican que la estructura laboral de las ciudades alemanas, tanto como las fluctuaciones del ciclo de los negocios, se reflejan en los planes laborales de la gente joven con un horizonte de clase obrera. Aporté también resultados al efecto, en que el trasfondo de la religión de la familia se relacionaba con los planes laborales de los jóvenes de clase media ${ }^{15}$.

En este trabajo temprano había otro aspecto destacado que ahora atribuía a Durkheim, aunque estoy seguro que por entonces no sabía de su existencia. En la introducción a Marienthal insistí en que quería estudiar "la ciudad desempleada y no los hombres desempleados». En otra frase se decía que, por esa razón, no se utilizaban tests de personalidad, sin especificar lo que quería decir

12 Public Opinion Quarterly, II (1947), 103-114.

13 La principal idea conceptual se tomó del psicoanalista Siegfried Bernfeld, el cual había caracterizado un valor creativo de la adolescencia de clase media con el nombre de "pubertad alargada». Los sociólogos norteamericanos han tomado recientemente esta noción con la designación de "gratificación diferida». La relación entre Bernfeld, Bühler y yo mismo está descrita en una monografía de Leopold ROSEMAYR (actualmente profesor de Sociología en la Universidad de Viena) sobre la investigación de la primera adolescencia en Austria: Geschichte der Jugendforschnung, 1914-1931 (Viena [1962]).

${ }_{14}$ Herbert Gans, "Urban Poverty and Social Planning», en Paul F. Lazarsfeld y otros (eds.), The Uses of Sociology (Nueva York, 1967).

15 Una tabla similar se utilizó al mismo tiempo por Robert MERTON en su disertación Science, Technology and Society in Seventeenth-Century England (Brujas, Bélgica, 1938). Supongo que ambos recibimos la idea de Max Weber, aunque yo no recuerdo efectivamente si en ese momento conocía la tabla sobre religión y elección profesional, que Weber incluyó en una nota a pie de página en su monografía sobre la ética protestante. 
con esa expresión. Pero la implicación estaba clara: que la estructura social tiene predominio sobre las variaciones individuales.

Se puede encontrar otro rasgo del ambiente político en la insistencia en la toma de decisiones. La posición austro-marxista puso todas sus esperanzas en el triunfo de las elecciones antes que en la creencia comunista en la violencia, y por eso tenía un gran interés en saber cómo votaba la gente. A partir de este punto se produjo un desplazamiento funcional importante y curioso. En esa época, la Universidad de Viena era dogmáticamente conservadora, y habría sido torpe para sus miembros directivos emprender sin riesgos el estudio de las decisiones electorales de la gente. Como sustituto consciente, desplacé la cuestión a preguntar cómo la gente joven desarrollaba sus planes laborales. Se reunió una serie de estudios de casos detallada con la ayuda de un grupo de estudiantes. Pero entonces me tuve que enfrentar a la bien conocida dificultad del análisis.

Durante algunos meses no sabía cómo proceder, hasta que finalmente - de una manera extraña- encontré una solución. Entre los estudiantes que trabajaban conmigo, una mujer joven llamó la atención de uno de los primeros expertos norteamericanos en investigación de mercados. Necesitaba hacer algunas entrevistas por entonces en Austria y, en razón de la formación de esta estudiante (posteriormente fue mi principal colaboradora en el trabajo de campo del estudio sobre Marienthal), se le pidió que hiciera algunas entrevistas sobre por qué la gente compraba diversas clases de sopa. La investigación de mercados era entonces completamente desconocida en Austria, y ella me habló de este encargo como algo curioso. Inmediatamente lo relacioné con el problema de la elección laboral. La dificultad estaba, obviamente, en que esa elección se desparramaba en muchas ramificaciones y retroalimentaciones. Si yo deseaba combinar el análisis estadístico con las descripciones de todos los procesos electivos, en adelante lo mejor sería concentrarme en materiales más manejables. Para la meta metodológica que tenía en la cabeza, las elecciones de los consumidores serían mucho más a propósito.

Ése es el inicio de mis estudios vieneses de investigación de mercados: el resultado de la equivalencia del voto socialista y la compra de sopas ${ }^{16}$.

He aprendido, además, lo suficiente de mis estudios de casos sobre aspiración laboral para construir un punto político más en Jungen und Beruf. Las implicaciones para una sociedad planificada estaban claras: la mayoría de la gente joven no había decidido planes laborales y, por eso, no se había hecho a la idea de estar siendo llevada - tan cuestión de hecho como tener que estar siendo llevada - hacia una elección laboral; en consecuencia, debería ser fácil cumplir las cuotas laborales establecidas mediante un plan económico central.

${ }_{16}$ Precisamente antes de venir a este país publiqué un artículo sobre «Art of Asking Why» —National Marketing Review, I (1935), 32-43_, que compendia las técnicas de entrevistar resultantes. Aunque reimpresa y ampliamente citada, no estoy seguro de que haya tenido gran influencia en la investigación norteamericana. Sin embargo, véase la extensa entrada "Reason Analysis", escrita por mi antiguo estudiante Charles KADUSHIM, en la nueva International Encyclopedia of the Social Sciences (Nueva York, 1968). 
2. El ambiente intelectual. He mencionado algunos de los episodios que me condujeron hacia los estudios empíricos. Dada esta inclinación, es relevante clarificar el perfil específico que adquirió el ambiente europeo en el cual comencé mi primer trabajo profesional, porque es ésa la fuerza que ayuda a explicar el papel que estaba destinado a desempeñar en los Estados Unidos.

Los Bühler, en el nuevo Instituto de Psicología de la Universidad de Viena, habían comenzado a centrarse en la integración de diferentes enfoques, lo que se ejemplariza en el importante libro de Karl Bühler, Die Krise der Psychologie. Su autor resultaba importante como introspeccionista, y también como un buen conocedor de la tradición de la filosofía de la cultura, y especialmente del pensamiento de Wilhelm Dilthey, como consecuencia de su amplia formación filosófica; además, durante una estancia en los Estados Unidos se había puesto en contacto con el conductismo norteamericano. Su libro significa un esfuerzo para analizar estas tres fuentes del conocimiento psicológico: introspección; interpretación de productos culturales tales como arte, folklore, biografías y diarios; y la observación de la conducta. Pero la clave del pensamiento de Bühler consistía en la necesidad de superar cualquier enfoque singular o cualquier material de información concreto para alcanzar una amplia integración conceptual.

Me resulta difícil decir ahora si me influyó realmente el espíritu ecuménico, pero ciertamente nunca pierdo la ocasión de poner de manifiesto que incluso estudios "triviales» — si se analizan e integran adecuadamente- pueden conducir a resultados importantes; «importante» implica un más alto nivel de generalización. De este modo resumí una vez un cierto número de estudios de consumidores construyendo la noción de consumidor proletario, el cual es

«... menos móvil psicológicamente, menos activo, más inhibido en su conducta. El radio de tiendas que tiene para posibles compras es más reducido. Compra con más frecuencia en la misma tienda. Sus hábitos alimenticios son más rígidos y menos sirvientes de las variaciones de estación. Como parte de esta limitación en las dimensiones efectivas, su interés en otras cosas que no sean los detalles más esenciales está perdido; exigencias en relación con la calidad, la apariencia y otros rasgos de las mercancías son menos específicas y frecuentes a medida que tratamos con consumidores de los estratos sociales más bajos».

Uno de los estudios que contribuyó a elaborar la noción del consumidor proletario se refería a las preferencias por el chocolate dulce o amargo; la gente de renta baja prefería el primero (y muy generalmente prefiere olores dulces, colores recios y otras experiencias de sentido fuerte). Y, sin embargo, ese estudio también pone de manifiesto que se puede con bastante facilidad omitir un punto importante. El presidente patrocinador del estudio se reunió con los directivos del Centro de Investigación de Viena y en la primera reunión nos ofreció un curioso testimonio de cómo el estudio había incrementado las ven- 
tas de la sección de chocolate. Sin embargo, de hecho, el estudio no había sido presentado todavía, y lo que pude concluir fue que quería ayudarnos con esta observación. Ahora sé lo que realmente había pasado: fallé al descubrir el Efecto Hawthorne; la sección del chocolate se vio tan implicada en nuestro estudio que sus miembros simplemente se mostraron muy activos y vendieron más.

En conjunto, las compras de los consumidores se convirtieron en un caso especial de un problema que tenía gran veneración en la tradición humanista europea: Handlung, la acción ${ }^{17}$. El mismo Bühler había escrito un trabajo fundamental sobre el lenguaje como una forma especial de acción ${ }^{18}$, y en estos términos informé sobre la naturaleza de los estudios de mercado austríacos cuando llegué a este país ${ }^{19}$. En "The Psychological Aspect of Market Research" (1934) incluí media docena de páginas sobre unos diagramas de «la estructura del acto de comprar» y nuevos términos ("Acento no Motivación») intercalados con — si se me permite decirlo así- ejemplos interesantes sobre la compra de sopas y jerseys. La idea general era que «la acción de comprar está singularmente articulada y que se pueden distinguir en ella fases y elementos diferentes». La tendencia a deducir una "perspectiva teórica» a partir de datos específicos se puede ejemplificar con la siguiente cita:

«El "tiempo de deliberación", los "rasgos anticipados de la compra", "la relación con previas compras" sólo son ejemplos de lo que podemos llamar las "coordinadas" psicológicas de una compra. Me parece que una de las contribuciones importantes de los psicólogos al problema de la investigación de mercados —el estudio general de la estructura de la compra-, nos prepara para encontrar en un estudio específico lo que posiblemente sea característico del material investigado».

Sería inaceptable informar sólo de que X por ciento de la gente hizo o pensó esto o aquello sobre un asunto. La tarea consiste en combinar diversos resultados en un número pequeño de "constructos integrantes». $\mathrm{Al}$ mismo

17 He señalado la importancia de la noción de acción en un artículo leído en el centenario de Max Weber organizado por la American Sociological Association (ASA): Paul F. LAZARSFELD y A. R. ObersChall, «Max Weber and Empirical Social», American Sociological Review, 30 (1965), 185-192.

${ }^{18}$ En Francia la «lingüística estructural» está hoy considerada como la mayor gloria de la ciencia social moderna. El padre fundador es Ferdinand de Suassure y la segunda generación está representada por el Círculo de Praga, con Troubetzkoy y Jakobson como cabezas principales. El último corrobora mi memoria sobre que él y sus asociados viajaban frecuentemente a Viena para obtener sabios consejos de Karl Bühler.

19 Publicado en la Harvard Business Review en octubre de ese año. La estructura de la Universidad de Viena me clasificó como "psicólogo». El hecho de que seis años más tarde llegara a ser miembro del Departamento de Sociología en Columbia no cambió el carácter de mi trabajo. Ahora soy profesor de ciencia social, lo que me resuelve el problema de una terminología embarazosa. Incidentalmente, el artículo citado fue rechazado por dos revistas de psicología, que consideraron el tema no apropiado psicológicamente. 
tiempo, era imperativo explicar tan claramente como fuera posible los procedimientos mediante los cuales se había alcanzado esa mayor profundidad ${ }^{20}$. En un artículo escrito en 1933, resumiendo la experiencia austríaca, se individualizan y se ejemplifican las siguientes cuatro reglas:

a) Para cualquier fenómeno debemos disponer de observaciones objetivas e informes introspectivos.

b) Los estudios de casos deben combinarse adecuadamente con información estadística.

c) La información contemporánea se debe completar con informaciones de fases anteriores de lo que está siendo estudiado.

d) Se deben combinar "datos naturales y experimentales». Entiendo por «experimental» principalmente cuestionarios e informes solicitados, en tanto que "natural» quiere decir lo que ahora se llama «medidas noostrusivas» — datos derivados de la vida cotidiana sin la interferencia del investigador.

La mera descripción no era suficiente. Para penetrar "detrás» de ella hay que recoger una cierta variedad de datos sobre cualquier tema que se esté investigando — precisamente como la verdadera posición de un objeto distante sólo se puede encontrar observándolo desde diferentes sitios y direcciones-. No es probable que yo fuera completamente consciente de las reglas subyacentes a la tradición investigadora vienesa tal como se desarrolló. Pero su estructura estaba lo suficientemente cerca de su superficie como para que yo pudiera articularla con alguna facilidad (cuando he tenido el placer de reflexionar sobre nuestro trabajo aquí, en este país).

Los esfuerzos para desarrollar una teoría de constructos integrantes — su naturaleza lógica-, y cómo éstos llegaron a ser parte de la necesidad de legitimar el trabajo empírico. En esa época, yo no conocía varios trabajos de Tönnies en los que intentaba introducir la idea de la sociografía en la tradición de los sociólogos germanos. Sería interesante hoy comparar estos dos desarrollos con más detalle. Algunos críticos se oponen hoy a la investigación por encuesta

${ }^{20}$ Este artículo — titulado «Principles of Sociography»— fue sometido a examen en 1934 en la revista de la New School for Social Research. Los profesores del Centro dieron la bienvenida al exponente de las ciencias sociales europeas, y pensé que los editores estarían interesados en un artículo que intentaba entrelazar explícitamente el trabajo empírico hecho en ambos países. Sin embargo, supongo que esa "sociografía» en ese momento no estaba considerada como una parte real de la tradición europea. El artículo original fue rehusado y no se publicó nunca. Releyéndolo ahora para este ensayo, lo encuentro (y especialmente los ejemplos que allí se contenían) característico del estado de cosas en los primeros años treinta. De paso, el término "constructo integrante» se llamó originalmente leitformel y se tradujo primero como «fórmula matriz». Sin embargo, el término "matriz» se identificó con el utilizado en el álgebra. Pero prefiero la traducción actual. Algo después se publicó un tratamiento extenso de los constructos integrantes en Allen H. Barton y Paul F. LAZARSFEld, "Some Functions of Qualitative Analysis in Social Research», Sociologica, I (1956), 321-351. 
como restrictiva y limitada, señalando a la tradición de Columbia como una mala influencia ${ }^{21}$. Sería útil señalar que, desde sus comienzos, esta tradición subraya la importancia de enfoques diversificados. La legitimación, como el trabajo del ama de casa, nunca parece que se ha hecho.

3. La ecuación personal. El elemento personal es inevitable. ¿Qué es lo que me convenció a mí de que una combinación de «intuición» y cuantificación era crucial para las ciencias sociales? En la introducción a Marienthal apareció esa combinación casi como un deber moral. Por eso he expresado mi insatisfacción con las estadísticas del desempleo, tanto como con una descripción casual de la vida del parado en los periódicos y la literatura. Y así escribí:

«Teníamos la idea de encontrar procedimientos que pudieran combinar el uso de datos numéricos con la inmersión [Sich einleben] en la situación. Para conseguir este fin lo siguiente es necesario: teníamos que lograr un contacto tan cercano con la población de Marienthal como para poder conseguir los detalles más pequeños de su vida cotidiana; al mismo tiempo, teníamos que percibir, cada día, todo lo que pudiera ser susceptible de reconstrucción objetiva; finalmente, para el conjunto teníamos que desarrollar toda la estructura, de modo que todos los detalles pudieran ser vistos como expresiones de un mínimo de hechos básicos».

Es bueno hacer notar las formulaciones de estas frases — que implicaban un imperativo para realizar esta misión metodológica-. Como todos los misioneros, no sentíamos que necesitásemos una justificación más allá de lo que las voces nos ordenaban hacer. Silenciosamente, la posición se iba esparciendo. En un apéndice al trabajo de Marienthal sobre la historia de la sociografía, Hans Zeisel presentó una recensión de seis páginas del American Survey, donde señalaba que los estudios de Chicago «por alguna extraña razón no se dedican al análisis estadístico de sus datos». A partir de este texto, no pudo Zeisel encontrar más que unos pocos ejemplos de la cuantificación de pautas complejas. Su recensión concluye con los siguientes puntos de atención, que son un eco del programa mencionado antes:

«La sociografía norteamericana no ha alcanzado una síntesis entre la estadística y una descripción completa de observaciones concretas. En trabajos de impresionante conceptualización — por ejemplo, en The Polish Peasent - la estadística está completamente ausente; por el contrario, las encuestas estadísticas son con frecuencia de una naturaleza rutinaria rechazable».

${ }^{21}$ Arthur Vidich, Joseph Bensman y Maurice Stein (eds.), Reflections on Community Studies (Nueva York, 1964). 
No puedo referir esta urgencia por cuantificar a experiencias complejas y pautas de conducta ni a ninguna influencia externa que prevaleciera en esa época. En esas condiciones, el historiador se ve forzado a buscar elementos idiosincrásicos; y éstos están disponibles en abundancia. Recuerdo mi excitación cuando - hacia 1925 - vi en el escaparate de una librería un diagrama desplegado en una de las primeras monografías germanas sobre análisis de correlaciones. Unos años más tarde, el sociólogo alemán Andreas Walter me mostró un mapa ecológico que había traído de un reciente viaje a Chicago, y tuve la misma reacción. El siguiente episodio seguía esa dirección. A la edad de veinticuatro años, más o menos, escuché a un líder del Movimiento de los jóvenes obreros socialistas, que leía un cuestionario que él les había distribuido: utilizaba citas individuales para describir la miseria de la vida en una factoría. Inmediatamente le pregunté que por qué no cuantificaba; le sorprendió la idea, y me entregó los cuestionarios. Hice un análisis estadístico, que después constituyó la base de mis primeros artículos. También presenté un informe en uno de los primeros seminarios de Bühler, quien fijó en mí su atención ${ }^{22}$.

Mi trabajo siguiente para Charlotte Bühler reforzó esta tendencia. Sus estudios principales sobre psicología infantil adoptaron una posición intermedia entre el norteamericano Gesell y el suizo Piaget. Este último realizó sus famosas observaciones semiexperimentales en sólo algunos niños, obteniendo de ellas teorías sobre el desarrollo de largo alcance; Gesell hizo observaciones estadísticas minuciosas sin esbozar ninguna generalización. La fama de Charlotte Bühler se basaba en una teoría de las fases, que "entrelazó» con observaciones estadísticas. En un punto de su posición me influyó en un modo que encerraba consecuencias de largo alcance: para mi trabajo Jungen und Beruf coordiné un gran número de datos de fuentes diferentes hasta formar un sistema coherente de conceptos. A Charlotte Bühler le agradó, y también aceptó mi posición sobre la necesidad de distinguir entre los adolescentes de clase media y los de clase obrera. Pero me objetó terminantemente el tono en que había escrito la sección sobre los jóvenes proletarios. Yo estaba ciertamente lleno de compasión, hablando de la explotación por la sociedad burguesa, y el estilo sermonario de esta sección era completamente diferente del resto del manuscrito. No pude negar este hecho y, finalmente, lo volví a escribir. Ninguno de los argumentos dejó de figurar, pero el tono se transformó en descriptivo y naturalista, en vez de crítico. No tengo ninguna duda de que este episodio

${ }^{22}$ Cuando yo tenía aproximadamente quince años leí las memorias de Lili Braun. Describe unas elecciones en Alemania en los primeros años de 1900, en que todos estaban esperando los resultados, y celebrando la victoria socialista. Esto me pareció extremadamente interesante en el verano de 1916, y cuando yo estaba escoltando a Rudolf Hilferding, el líder socialista, le solicité que me explicara lo que era todo aquello de esa elección. Encontró ni actitud más bien infantil, y me dijo que primero debía conocer el programa socialista. Llegamos al compromiso de que debía leer un libro de Kautsky y, al mismo tiempo, un libro sobre elecciones. Leí muy seriamente a Kautsky, y al tiempo no sabía nada, pero por lo que se refiere al librillo que explicaba las elecciones, quince años después todavía recuerdo el nombre del autor: Poensgen. 
afectó a mis escritos posteriores, y es un factor que contribuye al debate sobre el papel de la Sociología, que más tarde lideró C. Wright Mills.

\section{LA ORGANIZACIÓN DE LA INVESTIGACIÓN SOCIAL}

Hoy en día, los rasgos principales de un Centro de Investigación son bien conocidos. Existe una división del trabajo en la tarea esencial: escribir y hacer ante-pruebas de los cuestionarios, analizar tablas y elaborar informes. Coordinar y dirigir este trabajo es a la vez un reto administrativo (o de gobierno) e intelectual. Ser director del Centro es probablemente un nuevo tipo de profesional al que recientemente se le ha dado el nombre de "gerente académico». La naturaleza del trabajo requiere una relación más jerárquica entre los profesionales que participan que la que es habitual en un Departamento universitario.

En el contexto de esta memoria sobre lo que hay que indagar es la manera de acertar con este tipo de organización en los últimos años veinte. Ello se debe en parte — creo- a que yo y muchos de mis colaboradores tuvimos la experiencia del trabajo en equipo dentro del partido socialista y en el movimiento juvenil; en mi caso, me parecía que este estilo de trabajo era —al menos en parte - un sustituto psicológico de las actividades políticas. Pero el ejemplo de Charlotte Bühler también representó un papel importante. Ella tenía una habilidad prusiana para organizar actividades en grupo de muchas gentes y en muchos sitios. Algunos se sentían explotados por ella, pero yo siempre aprecié su buena preparación y ayuda.

El problema de la financiación de tales Institutos es hoy bien conocido. El dinero había que pedirlo a instituciones públicas y a la industria privada; lo cual era mucho más difícil hace cuarenta años, porque no había ni fundaciones ni reducción de impuestos y — hablando de todo- la idea de la investigación no estaba ampliamente aceptada. Se dependía de unos pocos individuos y se estaba en perpetua crisis económica. Yo formé un Consejo para el Centro que se componía de representantes de todos los grupos políticos e industriales en Viena ${ }^{23}$.

Todo esto hoy puede parecer más bien obvio, pero entonces se miraba con cierta sorpresa. Esto se puede ver en un documento que resulta interesante en muchos aspectos: en la revista de Sociología que entonces dirigía, en Colonia, Leopold von Wiese, en el último número antes de que fuera suspendida por el gobierno de Hitler, Von Wiese escribió una recensión más bien larga de Marienthal. Él, como otros profesores de Sociología y Economía, empleaban las largas vacaciones de Pascua para organizar con los estudiantes visitas a pue-

23 La reunión de 1967 de la World Association of Public Opinion Research se celebró en Viena, y un día se dedicó a conmemorar el cuarenta aniversario del Centro de Viena. Hans ZEISEL describió sus comienzos, y se publicó en la Revue Française de Sociologie, 2 (1968). 
blos y fábricas (una monografía de Von Wiese, titulada $E l$ pueblo, fue el resultado de una de esas visitas). En su recensión subrayaba con aprobación la diferencia entre esta tradición y nuestra empresa más organizada:

«Mis propios esfuerzos se limitan a ser de naturaleza meramente deductiva; sólo podemos asumir que los estudiantes que viven unos pocos días con la población local obtienen estímulos y conocimientos que - espero- les serán útiles más tarde o cuando hagan un estudio más extenso. La empresa de Viena tenía una estructura con unos observadores más avanzados y mejor formados teóricamente que pudieran dedicarse a su tarea durante un período de tiempo más largo (la participación de médicos locales era útil) hasta el punto de poder lograr resultados científicamente valiosos, que irían más allá del simple propósito de adiestrar estudiantes».

Von Wiese sospechaba que los fondos de que disponían los Bühler, procedentes de sus conexiones norteamericanas, harían posible este sistema más amplio. De hecho, esos fondos sólo representaron un papel muy pequeño. A los que contestaban los cuestionarios, por el tiempo que nos dedicaban, se les pagaba con un regalo de ropas de segunda mano que recogíamos en Viena. La supervisión y el análisis se realizaron por compañeros universitarios del profesorado que nos hacían el regalo de su tiempo. Sólo teníamos una pequeña cantidad para gastos procedente del Consejo central del sindicato.

Von Wiese planteó dos objeciones metodológicas. No fue de su aprobación que se utilizaran términos psicológicos en un trabajo que él consideraba esencialmente sociológico; no tenía conocimiento de la estructura de la Universidad de Viena, a que he aludido antes. Y respecto de nuestra posición básica, formulada en la introducción a Marienthal, comentó lo siguiente:

"Considero como una concesión demasiado grande a los estadísticos, que los autores propongan "rechazar todas las impresiones para las que no se tengan pruebas cuantitativas". Afortunadamente, no han sido demasiado estrictos en la aplicación de este principio».

La compleja reacción de Von Wiese me parece una indicación particularmente clara de que la Sociología germánica estaba empezando a adoptar un nuevo giro en el momento en que fue suprimida - a todos los efectos prácticos- por los acontecimientos políticos.

El Centro vienés fue una sucesión de improvisaciones, y el elemento básico de la organización de la investigación se desarrolló lentamente. A pesar de un cierto número de formalidades externas, nunca se consolidó como una organización estable. Sólo cuando ya estaban en la Universidad de Newark los diferentes componentes - todos concurrentes en mi cabeza - se pudieron integrar en cierto tipo de plan institucional. A pesar de ello, los comienzos en América fueron caóticos. 
En el verano de 1935 se me obligó a volver a Viena para cambiar mi permiso de estudiante por un visado de inmigración. En octubre, pocas semanas después de mi llegada, recibí un aviso de Robert Lynd sobre que la Administración de vacaciones de Nueva Jersey había recogido diez mil cuestionarios de jóvenes entre catorce y veinticinco años para un proyecto de la Administración nacional de jóvenes, y necesitaba a alguien que analizara esos materiales. Ellos se habían dirigido a Frank Kingdon, que acababa de ser nombrado rector de la Universidad de Newark — una institución de tamaño reducido-, de la que se esperaba que se organizase como un espacio de educación superior para estudiantes de clase social modesta del Condado de Essex, en Nueva Jersey ${ }^{24}$. Kingdon tuvo la inteligente idea de que alguien pagado por la institución analizara las preguntas, y pudiera, al mismo tiempo, enseñar algunos cursos de investigación en la Universidad. Lynd me había recomendado para ese trabajo, y lo acepté con agradecimiento.

Kingdon y yo nos llevamos bien desde el principio. En la primera conversación sugerí que el plan debía ser ampliado, y el proyecto de la Universidad debía ser el principio de un Research Center of the University of Newark (Centro de Investigación de la Universidad de Newark), que propuse que se creara al mismo tiempo. Era obvio que la Universidad no podía contribuir económicamente sino indirectamente (dando espacio para trabajar, por ejemplo). Me hice a la idea de que para mantener el Centro vivo debíamos conseguir contratos, aunque Kingdon pudo más adelante ayudar asignando dinero de vacaciones para un gran número de estudiantes desempleados, para los cuales yo podía «inventar» trabajo.

Pasados unos pocos meses la situación se formalizó. El 19 de junio de 1936 me escribió Kingdon, en nombre del Consejo universitario, una carta oficial de contrato. En ella se decía:

«Se pone en su conocimiento que estamos ofreciéndole el puesto de Director ejecutivo del Centro de Investigación de la Universidad de Newark durante un período de doce meses a partir de 21 de mayo de 1936 y hasta 21 de mayo de 1937.

El sueldo básico para este puesto es de 4.800 dólares, pero la Universidad se obliga a pagarle la mitad de esa suma, y el resto se pagará de otras fuentes. El sueldo mensual que recibirá, pues, es de 200 dólares.

Una porción de este tiempo parcial debe estar disponible para la Universidad de Newark y puede ser asignado a la enseñanza. Pero la Universidad no le pedirá que enseñe más de ocho horas».

Supongo que éste es el primer documento que propone una posición aparte para un director de Centro de Investigación. Desgraciadamente, incluso hoy

${ }^{24}$ El plan nunca se llevó a cabo porque el muy capaz de Kingdon se metió en política y descuidó la institución. Cogido entre dos fuegos, acabó más bien trágicamente. En la actualidad, el edificio de la calle Rector aloja la rama local de la Universidad de Ritgers. 
en día se asume en muchas Universidades que el director es responsable en parte de su propio salario ${ }^{25}$.

Había muchos estudiantes en paro, y continuamente tenía que pensar en temas de trabajo para que estuvieran ocupados. Con la ayuda de mis contactos en el mercado obtuve las cifras de circulación (o distribución) de unas veinte revistas en las cien ciudades más grandes de los Estados Unidos: combinándolas con los datos del Censo y otras informaciones económicas, escribimos un artículo caracterizando las ciudades sobre la base del perfil de las revistas, que se publicó más tarde en uno de los primeros números de la revista que se acabada de crear, la Public Opinion Quarterly (1937) ${ }^{26}$. Al mismo tiempo empecé a establecer contactos con otras agencias. El superintendente de las escuelas del Condado de Essex costeó un estudio sobre los problemas de las escuelas locales, del que publicamos varias pequeñas monografías estadísticas. La WPA (Works Projects Administration) comenzó un gran proyecto sobre desempleo tecnológico — con sede central en Philadelphia—, y logré que me permitieran estudiar la ciudad manufacturera de vidrio de Millville, New Jersey, que había llegado a estar casi totalmente en paro como consecuencia de la introducción de maquinaria para soplar el vidrio, y la transferencia de la compañía principal a Ohio. Aunque este estudio nunca se concluyó a causa de falta de continuidad en los fondos, sin embargo, me fue posible en 1935-36 establecer un equipo directivo, y, por otra parte, el Instituto Horkheimer me ayudó a localizar algunos de sus trabajos en el Centro de Newark, y también al pagarme por la supervisión. Los resultados más conocidos de estos esfuerzos colaborativos se encuentran en el libro de Mirra Komarovski, The Unemployed Man and His Family (1940).

En la primavera de 1937 escribí un informe oficial para el Patronato de Newark en el que intenté explicar la idea completa de ese Centro, haciendo ver que sería valioso para la Universidad y que sería financieramente viable. Las metas de los estudios de campo del Centro de Investigación de Newark serían:

«ofrecer formación para la investigación a los estudiantes;

desarrollar nuevos métodos de investigación;

publicar estudios acabados;

ayudar a la ciudad de Newark a entender mejor sus problemas económicos y sociales;

actuar como servicio de consulta para las agencias sociales y mercantiles de la ciudad;

${ }^{25}$ El nivel muy bajo de los salarios se explica por la situación económica de aquella época. Sin embargo, ocho horas de clase a la semana por 200 dólares era -incluso entonces - probablemente un muy pobre medio de ganarse la vida académicamente.

26 Paul F. LAZARSFeld y Rowena Wyant, «Magazines in 90 Cities: Who Reads What?», Public Opinion Quarterly, I (1937), 29-41. En cada punto computé el promedio de todas estas cifras para desarrollar el perfil de la ciudad típica, que resultó ser Muncie, Indiana, la Middletown de Lynd. 
ofrecer a los estudiantes la oportunidad de obtener enpleo provechoso; acumular fondos para la continuidad y ampliación de las actividades del Centro;

hacer que la Universidad, como un todo, fuera mejor conocida local y nacionalmente».

Razoné que su utilidad se pudiera justificar de varios modos. Se pagarían salarios de hasta 1.500 dólares al mes a estudiantes y licenciados de la Universidad; ello no implicaba becas de vacaciones y se podía decir que se debía exclusivamente a la existencia del Centro. Alrededor de un centenar de artículos de periódicos hicieron referencia a su trabajo. «El Centro y [por ello] la Universidad de Newark está representada por su director en toda una serie de comités regionales y nacionales». Y entonces enumeré diez estudios en marcha. En este catálogo incluí todo aquello a lo que yo estaba asociado, incluyendo algunos artículos que había publicado y estudios comerciales con los que - como consultor personal- estaba relacionado ${ }^{27}$.

Hacia 1936 el Centro de Newark llegó a ser conocido como una curiosidad. Cierto día, Everett Hughes y Robert Park vinieron a verlo —un honor que no supe apreciar completamente en su momento-. George Lundberg (Bennington) y John Jenkins (Cornell) me enviaron estudiantes para que los formase, entre ellos Edward Schuman, que estuvo conmigo hasta que Samuel Stouffer lo incorporó al "War Departament» («Departamento de Guerra»). Pero el principal indicador de un interés público creciente consistió en el hecho de que, en la primavera de 1937, yo fuese considerado como posible candidato a la dirección del principal Proyecto de Investigación sobre Comunicaciones Masivas, que la Fundación Rockefeller iba a patrocinar ${ }^{28}$.

A lo largo de todo el curso del desarrollo institucional, su rasgo característico fue la metodología de la investigación. En mi discurso como presidente, dirigido a la Asociación Norteamericana de Sociología (ASA), expresé este punto de una manera que quizás fue un poco exagerada, pero que contiene

${ }_{27}$ También se incluía mi trabajo para el Social Science Research Council sobre los efectos de la Depresión. Se planearon (y realizaron) trece monografías sobre diversos efectos que se basaron en la recogida e integración de estudios disponibles. Se nombró director a Stouffer, y solicitó de Lynd que recomendara a alguien para la monografía sobre la familia. Por sugerencia de Lynd, Stouffer me invitó a Chicago, y la primera reunión duró prácticamente todo el día. A las pocas horas habíamos establecido un plan conjunto, y a partir de esas fechas prosiguió mi colaboración continua con él, a lo que volveré frecuentemente. Véase Samuel STOUfFer y Paul F. LAZARSFELD, Research Memorandum on the Family in the Depression (Nueva York, 1937).

${ }^{28}$ Por entonces tuve bastante claro que un director de investigación necesitaba tener un nuevo tipo de capacidades para las que pocas personas habían sido preparadas. Las especificaciones y preparación para este puesto habían sido para mí durante muchos años una cuestión de gran preocupación. En mi discurso presidencial a la Asociación Norteamericana — «The Sociology of Empirical Social Research», American Sociological Review, 27 (1962), 757-767- debatí el problema con gran detalle. El cual me parece todavía importante e irresuelto. Por ello acompaño las secciones correspondientes de ese dicurso como apéndice a este ensayo. 
— creo- una verdad esencial. Supervisando incluso un pequeño grupo de investigación, uno se hace una idea bastante exacta de las diferencias entre los diversos elementos de la operación investigadora y de la necesidad de integrarlos en un producto final. Algunos ayudantes son buenos para entrevistas temáticas, otros están dotados para el manejo de tablas estadísticas, otros finalmente son especialmente buenos para rebuscar posibles contribuciones en la bibliografía existente. Los diferentes papeles tienen que ser explícitos; cada uno tiene que saber lo que se espera de él y el modo cómo su tarea se relaciona con el trabajo de los demás. La formación de los investigadores rápidamente se torna en explicación metodológica. Este punto está tal vez cercano a la clase de Sociología del conocimiento que los marxistas emplean cuando debaten sobre que los nuevos instrumentos de producción se reflejan frecuentemente en nuevos modos de análisis intelectual.

Todo esto deja abierto el camino a la cuestión sobre el modo en que una forma organizativa desarrollada en Viena se convirtió en algo relativamente fácil de ser aceptado y difundido en otro país. Para interpretarlo tengo que volver a los dos años de mi beca (de 1933 a 1935).

\section{LA TRANSFERENCIA ATLÁNTICA DE RASGOS DE DIRECCIÓN}

El impacto de los intelectuales europeos en los Estados Unidos se puede estudiar de muchas maneras. Un enfoque consiste en examinar ciertos campos antes y después de la llegada de individuos específicos; otro, rastrear los contactos que el inmigrante tuvo y las referencias que los norteamericanos le hicieron o bien de sus propias publicaciones o bien en las comunicaciones solicitadas especialmente para este fin. Un tercer enfoque sobre el fenómeno de transferencia consiste en examinar el modo en que el inmigrante mismo percibió la situación. ¿Cuál fue su estrategia y su experiencia? Dado que la mayoría de los hombres de los que trata este volumen ya no viven, parece procedente que los pocos que sobreviven proporcionen información sobre el modo en que vieron esa secuencia de hechos, vistos desde dentro.

La idea de un "testigo experto", descrita en la Introducción, es especialmente útil para este tercer enfoque: éste informa sobre sus experiencias concretas y, al mismo tiempo, trata de conceptualizarlas, para debatir episodios dentro de pautas coherentes. Pero en este caso el lector debe recordar que los otros participantes pueden ser también considerados testigos ${ }^{29}$. Los historiadores

${ }^{29}$ El lector puede comparar, por ejemplo, mis informes y los de Adorno sobre los mismos hechos. Para ampliar esta situación, quiero añadir unas pocas líneas sobre Kurt Lewin, al cual admiraba tanto en Viena como aquí. Lewin había adquirido fama en Alemania a través de una serie de trabajos escritos en parte por él y en parte por sus discípulos. Estos trabajos aparecieron durante varios años con el título general de Psicología de la acción. La noción de la acción, que disfrutaba de un alto prestigio en Alemania, era inaceptable aquí por la dominancia del conductismo. Cuando Lewin finalmente vino a este país, se interesó por el tema que le hizo famoso 
pueden desenterrar más documentos, entrevistar a otros participantes y llegar a conclusiones bastante diferentes de las mías. Aquí no hay ningún veredicto final, sólo una interpretación de lo que pudiera llamarse «estrategia»: los movimientos que el actor hace más o menos consciente e intencionadamente; las motivaciones generales que guían sus reacciones y elecciones; y el carácter de la situación total, incluso cuando el actor no era consciente de lo que pasaba en aquella época. Quizás el término «estrategia latente» servirá mejor ${ }^{30}$.

El comienzo de este tipo de análisis se encuentra en lo que podemos llamar rasgos de dirección. ¿Qué es lo que la persona sabe sobre el país al que viene antes de su llegada? ¿Quién cambió primero? ¿Qué experiencia anterior guió sus primeros movimientos?

Yo puedo resumir mi experiencia en tres líneas que al principio eran muy distintas, pero que al final tendieron a converger: la continuación de mi interés en la investigación del desempleo; y mi deseo de ayudar al Centro de Investigación de Viena, estableciendo contactos para él con relevantes organizaciones en este país.

El estudio sobre Marienthal fue recibido con alguna atención a través de dos canales. Un psicólogo norteamericano que estuvo como profesor visitante en Viena había visto algunos materiales de ese estudio y a su vuelta escribió un artículo en el Nation titulado "Cuando hombre come perro-caliente». En el Congreso de Psicología de 1932, en Alemania, Charlotte Bühler me permitió estar en el programa; informé de los primeros resultados y algunos prominentes norteamericanos —incluyendo a Gordon Allport, Otto Klineberg y Goodwin Watson - me visitaron para obtener algunos detalles. Fueron ellos algunos de los primeros que vi cuando vine a los Estados Unidos ${ }^{31}$.

Cuando comenzó mi beca, la Federal Emergency Relief Administration (FERA) (Administración de Ayudas Federales de Urgencia) ya había establecido su primera unidad de investigación. La Fundación Rockefeller encontró para mí un trabajo allí como voluntario. Para hacerlo me trasladé a Washington y mientras estuve allí encontré a algunos sociólogos trabajando como consultores gubernamentales; éstos pertenecían al grupo emergente de empiristas que pronto crearon la Sociological Research Association (Asociación de Inves-

aquí, especialmente «la dinámica de grupos». J. L. Moreno reclama que fue él quien aconsejó a Lewin que adoptara este término. En 1938 me visitó un reciente refugiado vienés, Gustav Bergmann, quien me pidió ayuda. Recordé que era un gran matemático con gran interés en la psicología. Por entonces, Lewin estaba ya en Iowa. Le telefoneé y sugerí que se le diera un empleo a Bergmann, que pudiera ayudarle a establecer sus ideas topológicas en armonía con los procedimientos predominantes en tipología matemática. Lewin lo hizo, ciertamente; lo invitó, pero la aventura acabó en desacuerdo entre los dos. Bergmann todavía enseña lógica y filosofía de la ciencia en Iowa, y ha publicado asiduamente sobre la naturaleza de la teoría filosófica.

${ }^{30}$ En otra parte he subrayado que esa noción general de estrategia debe ser considerada con más seriedad en el análisis sociológico: «Innovation in Higher Education», en Expanding Horizons of Knowledge About Man (Nueva York, 1966).

${ }_{31}$ Mi presentación en el Congreso se publicó en traducción al inglés como «An Unempoyed Village» en la revista Personality and Character (1933). 
tigación Sociológica) como punta de lanza de su posición en la American Sociological Society (Sociedad Sociológica Norteamericana). Estos hombres trabajaban principalmente con muchos datos de tipo censal. A causa del siguiente episodio alcancé alguna reputación en este grupo como una clase diferente de técnico: la FERA iba a publicar una monografía que ponía de manifiesto una correlación estrecha entre desempleo y educación; sugerí que el resultado pudiera ser el efecto espúreo de la edad, una idea que hoy en día es un lugar común. Se hizo una tabulación cruzada y se puso de manifiesto, evidentemente, que el papel de la edad era muy importante: la gente con poca educación era la más vieja y la que tenía la tasa más alta de desempleo. Esto impresionó al grupo investigador de la FERA. Cuando estuve algún tiempo en Chicago, en la primavera de 1934, compusieron para mí una pequeña unidad de tabulación, que me ayudó allí en el análisis multivariante de sus estudios sobre desempleo.

Durante este período, primero dediqué algún tiempo a visitar los pocos sitios en que se enseñaba investigación social empírica. Fui a la Universidad de Rochester para conocer a Luther Fry, que había escrito el primer libro sobre técnicas de investigación social. Asistí a sus clases durante varias semanas, y organicé un estudio sobre el modo en que la gente decide las películas que ve ${ }^{32}$.

En esa época no pensaba de mí mismo en absoluto que era un sociólogo. No iba a reuniones regionales o nacionales de sociólogos, aunque mi beca me proporcionaba los fondos para ello. De hecho, yo sólo tenía una vaga idea de la situación de la Sociología en los Estados Unidos. Visité Chicago durante unas semanas, pero principalmente para trabajar con Arthur Kornhauser, un notable psicólogo aplicado. No tuve ningún recuerdo de ninguna reunión memorable allí, excepto un apreciable almuerzo con L. L. Thurstone. Estoy seguro de que no me encontré con Samuel Stouffer durante el primer año. El recuerdo más importante de la visita se refiere a una investigación de los profesores de la Universidad de Chicago que el Parlamento del Estado sostenía en ese tiempo; y recuerdo que me impresionó mucho Robert Hutchins.

Mi principal contacto sociológico en esa época era Robert S. Lynd. En razón de su obra Middletown, él fue una de las primeras personas a las que busqué; fue extremadamente generoso con el tiempo que dedicó a aconsejarme. El importante papel que representó en los primeros diez años de mi vida profesional en los Estados Unidos quedará meridianamente claro en lo que sigue de este ensayo ${ }^{33}$.

32 Más tarde, el cuestionario sirvió de modelo para el estudio Decatur que dio como resultado el trabajo de Elihu Katz y Paul F. LAZArsfeld, Personal Influence (Glencoe, Ill., 1955).

${ }_{33}$ Por lo que a mi trabajo se refiere, empecé un programa que nunca llegué a completar. Empezando con mis propias ideas en "The Art of Asking Why» y mi interés en la literatura alemana sobre el «querer», di comienzo al estudio de la literatura norteamericana sobre "motivación" y a escribir una monografía sobre el tema. Todavía tengo apuntes de resúmenes y notas sobre las publicaciones pertinentes. Visité también a William McDougall en Carolina del Norte para aprender más sus teorías de los sentimientos. En visión retrospectiva creo que era el cambio hacia los sociólogos norteamericanos como un nuevo grupo de referencia, que da razón de que mi primer plan se fuera al traste. Este cambio se hará aparente a medida que la historia prosiga. 
En este período mi principal preocupación era el Centro de Investigación de Viena, al que había dejado en condiciones financieras precarias. La situación se deterioró tras el putsch del gobierno de Dollfuss, quien consideró las actividades del Centro y su personal como subversivos, probablemente con razón. Mi gran esperanza era obtener fondos de organizaciones de investigación o de firmas comerciales norteamericanas que se interesasen en ayudar económicamente - al menos en parte- el trabajo en Viena. En ello empleé una gran parte de mi tiempo hablando con gente que trabajase en el campo de la investigación de mercados. Nunca tuve éxito en el intento de movilizar ayudas para Viena, pero mis esfuerzos tuvieron consecuencias importantes para mí - personalmente- Todo comenzó cuando algunos de los psicólogos que había contactado me comunicaron que estaban especialmente interesados en un nuevo despliegue de posibilidades.

Hacia 1930, un grupo de psicólogos norteamericanos —entre los que estaban E. L. Thorndike y J. M. Cattell- crearon una organización no-lucrativa con el nombre Psychological Corporation (PSC). Su plan consistía, de una parte, en promover la utilización de la psicología aplicada entre los hombres de negocios y, por otra parte, en proporcionar a los psicólogos universitarios oportunidades para la investigación y —supongo- ingresos adicionales. Cuando tuve conocimiento de ello me puse inmediatamente en contacto con el director de investigación de la PSC y me ofrecí a ayudarle.

Entonces la investigación de mercados norteamericana se basaba principalmente en contar curiosidades de un modo más bien simple. No obstante, esperaba de la PSC (por el estatus universitario de sus fundadores) que adoptara la misma posición sobre la investigación que nuestro grupo de Viena. Pero no fue así. La PSC tenía que luchar por su existencia, y sus actividades investigadoras consistían en simples encuestas de consumidores, en competencia con otras agencias comerciales. Consideré casi como una misión ayudarles en su investigación a ser pioneros en vez de rutinarios. A este fin propuse unos proyectos - siempre en la línea de por qué la gente hizo esto o lo otro-, pero nada resultó de estos esfuerzos. El director de la PSC, en el que se combinaba un radicalismo conductista con el deseo de que la organización ganara dinero, me objetó que mis cuestionarios eran muy largos. Suelo contar la anécdota de una mujer que quería comprar un perro: se sorprendió de que el más pequeño fuese el más caro, y finalmente preguntó lo que no tenía que pagar por ningún perro en absoluto. Se puede entender que, después de un tiempo, mis relaciones con la Corporación Psicológica fueran disminuyendo hasta evaporarse ${ }^{34}$.

${ }^{34}$ Éste pudiera ser un buen sitio para recordar una anécdota característica de una mala interpretación de normas y roles o papeles que claramente no ocurren sólo a los campesinos polacos. Cuando ofrecí mi colaboración al director de la PSC, me preguntó si sabía lo útil que era hacer uso de la regla de cálculo. Le contesté afirmativamente y me asignó la tarea de computar los porcentajes de su principal estudio - llamado Barómetro de Marcas-, que consistía en informes sobre las marcas de los alimentos que compraban las amas de casa norteamericanas, basándose en una muestra nacional. Como se comprenderá, encontré aburrido calcular porcentajes todos los 
Tales eran los principales rasgos de dirección que orientaban mis primeras actividades. A las que se añadían un cierto número de contactos personales, que significaron una parte importante del proceso de transferencia que estoy intentando describir, los cuales sólo se pueden entender como de interacción mutua. Ciertamente, será necesario volver hacia atrás y hacia adelante entre lo que yo pienso que eran tendencias prevalecientes en este país y ciertas pautas de conducta que traje conmigo.

\section{LA TRANSFERENCIA ATLÁNTICA-ESTRATEGIAS LATENTES}

Algunos jóvenes psicólogos consultaron a la Corporación Psicológica y, junto conmigo, formamos algo parecido al movimiento de los Jóvenes Turcos. El miembro de este grupo a quien vi con más frecuencia en esa época fue Rensis Likert, entonces profesor ayudante en la Universidad de Nueva York, el cual se interesó por el tipo de estudios complejos de mercados en Viena, y yo agradecí la traducción al inglés de un estudio mío sobre el té, que Likert realizó para sus estudiantes. Finalmente, Likert fue un ardiente abogado de la utilización exclusiva de entrevistas no-estructuradas, que nosotros en Viena combinábamos con datos estadísticos ${ }^{35}$.

Otro encuentro tuvo lugar con el psicólogo aplicado de Cornell, John Jenkins. Se interesó también en el tipo complejo de tabulaciones cruzadas que incorporábamos a nuestros estudios. En Viena trabajé en un manual mimeografiado para mis estudiantes con el título Cómo sacar partido a los números (Umgang mit Zahlen ${ }^{36}$; el título procede del libro, famoso en el siglo XVIII,

días. Pero con el tiempo «entendí» la situación: la cultura norteamericana requiere que cualquiera que trabaja aprenda desde lo más bajo; me estaban probando antes de ser admitido en trabajo profesional propiamente dicho. Después de algunos días pregunté tímidamente al director si había demostrado suficientemente mi resistencia. Sólo entonces entendió lo que era un becario de la Rockefeller europea. El director había entendido mi trabajo como algo que él no tenía que pagar, y probablemente me clasificó como si fuera alguien pagado por la WPA. Algo parecido me ocurrió con algunos de mis primeros viajes, que hice en tren, incluso de noche. Un día un contable de la Rockefeller me preguntó por qué no utilizaba el autobús, que era lo que me correspondía. No me había dado cuenta de que los autobuses existían; aprendí en Europa que en los democráticos Estados Unidos no había nada como la distinción europea entre diferentes clases de los coches de ferrocarril.

${ }^{35}$ Durante la segunda guerra mundial se desarrolló una situación paradójica: Likert era entonces director del Departamento de Agricultura, que dirigía los estudios de moral (cívica) entre los agricultores. Yo era consultor de la OWI (Centro de Información de Guerra), que hizo los estudios correspondientes en zonas urbanas. El director de investigación de la OWI era Elmo Wilson, que favoreció entrevistas altamente estructuradas. Batallas más bien vehementes se desarrollaron entre la OWI y el grupo de Likert. Se me pidió que estudiara el asunto y escribí un informe; se publicó más adelante de manera resumida con el título «La controversia sobre entrevistas de temas concretos -Una oferta de negociación», Public Opinion Quarterly, 8 (1944).

${ }^{36}$ Cuando Hans Zeisel vino a los Estados Unidos en 1938, le sugerí que ampliara este texto, y el Centro de Columbia se encargó de su primera publicación. Deseaba muy mucho encontrar un buen título norteamericano. Una vez en una tienda de flores vi un eslogan de promoción 
Über den Umgang mit Menschen, de Adolf von Knigge). Jenkins lo tradujo al inglés para sus estudiantes. Pasé mis vacaciones de verano de 1934 con él en Ithaca, y discutimos la idea de una «nueva imagen» para la psicología aplicada. Más adelante creó un Departamento especializado en este campo en la Universidad de Maryland.

Al mismo tiempo, la pequeña fraternidad de los expertos en investigación comercial de mercados se fijó en mi trabajo. En gran medida gracias a los esfuerzos de Percival White -el cual escribió uno de los primeros libros de texto sobre investigación de mercados-, se me invitó a las conferencias y a participar en los comités de la American Marketing Association (Asociación Norteamericana de Mercados), recién fundada. Ésta estaba a punto de publicar un libro de texto oficial - The Techniques of Marketing Research- y me encomendó escribir cuatro capítulos. Uno de ellos, sobre la interpretación, contenía referencias a la psicología profunda, y se considera generalmente como el comienzo de la «investigación de las motivaciones». El libro se utilizó cumplidamente en Facultades de Empresariales, y me ayudó más adelante cuando necesité ayuda para el trabajo de nuestra investigación sobre la radio.

Entonces aconteció que las primeras cuestiones políticas se infiltraron en los estudios comerciales de mercados. Hacia 1935, los sondeos empezaron a ser una actividad comercial independiente, que resultó interesante para los sociólogos, así como para los psicólogos. Mientras los primeros - los sociólogos- eran bastante amistosos, los segundos — los psicólogos- no lo fueron, porque la empresa se resentía demasiado del bajo nivel académico que tenía la "psicología aplicada»" ${ }^{37}$. Mis amigos sociólogos escuchaban con interés mis aventuras en el mundo de la investigación de mercados.

Al final de mi primer año de beca había desarrollado una red de contactos personales e institucionales entremezclada dentro de un margen más bien estrecho de actividades profesionales. Había realizado esfuerzos para ayudar al Centro de Viena, donde intentaba volver. Pero los acontecimientos políticos en Austria poco a poco me llevaron a la idea de permanecer en los Estados Unidos. Empecé a tratar a gente con la finalidad de ver las posibilidades de trabajar aquí en el otoño de 1937. Sólo un puesto de trabajo conectado con una Universidad era concebible. Pero el hecho de que yo había tenido un pie en el campo académico y otro pie en lo comercial se tradujo en una cierta cantidad de trapicheos, de lo cual es un ejemplo típico lo que sigue.

entonces muy en boga: «Dígalo con flores». Inmediatamente decidí que el título del libro debía ser Dígalo con números, y con este título apareció en 1947. En teoría social se llama su equivalente funcional. Zeisel entretanto había ampliado bastante la dimensión del libro; se ha traducido a varias lenguas, y ahora se encuentra en su quinta edición en los Estados Unidos.

37 En el otoño de 1933 me invitó Gordon Allport a hablar en su seminario sobre el problema de la motivación. Tras una presentación introductoria, dijo: «Permítame ofrecerle un primer ejemplo de un estudio sobre limpieza de boca». Hubo ruido de risotadas, y contesté: "No alcanzo a comprender por qué "levantar pesas" es mucho más digno que "lavarse los dientes"”. Pienso que Edwin Boring estaba presente y que esa noche pudiera haber sugerido esa apostilla. 
En la Universidad de Pittsburgh existía un Centro de Investigación que había sido creado por un hombre bien conocido en la investigación educativa: W. W. Charters. Estuve dos meses en este Instituto de Investigación de ventas al por menor, que al tiempo de mi visita estaba bajo la dirección de David Craig. Con éste, organicé algunos estudios sobre temas tales como «Cómo las mujeres de Pittsburgh deciden dónde comprar sus vestidos», o "Cómo los conductores de Pittsburgh seleccionan su gasolina $»^{38}$. (El primer estudio representó para mí una invitación como huésped en casa del millonario Edgar Kaufman, y el segundo supuso un reencuentro con Paul Mellon.) Por entonces, la mayor asociación comercial de tiendas de ventas al por menor se estableció en Washington; su presidente me consultó sobre quién debía ser el director de investigación y, a sugerencia mía, nombró a Craig. Cuando finalizaba el período de mi beca, Craig dimitió de su puesto en Pittsburgh y se trasladó a Washington. Antes de salir de allí me proporcionó un puesto temporal en su Instituto. El consejo directivo no se había reunido todavía, pero Craig me escribió una carta oficial de trabajo, que fue suficiente para obtener el visado de inmigración desde el Consulado norteamericano de Viena.

Todos estos mecanismos de transferencia los englobo en la amplia noción de estrategia latente. Me equivocaría seguramente si la redujera a una manipulación consciente. Todo esto tiene más bien el carácter de una vigilancia de fondo que conecta situaciones accidentales con finalidades latentes. Pero ello no es una explicación. Hay que añadir un elemento «libidinal» que haga todas esas cosas agradables dentro de sus propios límites. Estaba casi obsesionado con la idea de que yo quería estar conectado con tantos estudios como fuera posible, y me servía de cualquier ocasión para añadir otro más. De este modo, pronto obtuve fondos para estudiar el acomodo de nuestro grupo inmediato - los nueve becarios de la Rockefeller europea; los cuestionarios que utilicé en esa ocasión hace treinta años todavía están disponibles, y pudieran tener algún interés histórico- ${ }^{39}$.

Las estrategias latentes y los rasgos de dirección comprenden las interacciones que prevalecen siempre entre predisposiciones y situaciones. Las estrategias latentes llevan a una percepción selectiva del medio, y también cristalizan una autoconciencia más precisa, que me hizo tener éxito en una amplia secuencia de episodios. ¿Pero qué produjo una proporción relativamente alta de éxitos? Aquí tengo que recurrir a un término tal como adaptación estructural. Tanto el medio como el estilo de vida del inmigrante están pautados de una cierta

${ }^{38}$ Estos y otros estudios no publicados mencionados en este apartado se pueden obtener en forma mimeografiada en los Archivos de la Historia de la Psicología, en la Universidad de Akron (Akron, Ohio).

${ }^{39}$ Mirando hacia atrás, soy consciente del coste que implicaba mi estilo de vida. Durante los dos años apenas vi algo del país, excepto Centros de investigación, y también establecí pocos contactos sociales personales. Por entonces no había más investigación en la costa oeste, y probablemente soy el único de nueve becarios extranjeros que no ejerció su derecho de viajar a California. 
manera. Los elementos de estas dos pautas - medio y estilo de vida - se complementan entre sí y, en alguna medida, éste fue mi caso. En este sentido, en la Introducción ofrecí ejemplos de mis intereses cuantitativos, controlados por una formación conceptual intensa, acomodándose bien con ciertas tendencias nacientes en la comunidad norteamericana. Permítaseme ofrecer otros dos ejemplos de esa adaptación estructural. El primero pone de manifiesto el papel prospectivo de una idiosincrasia personal; el segundo pone de relieve la utilidad de un enfoque tangencial a las recompensas convencionales.

En una carta a Viena, de la que tengo copia, informé — durante mi primer año de beca- que «encuentro muy interesante encontrarme con lo que puede llamarse gente de segunda-fila; cuando llego a un sitio nuevo presento mis respetos a los grandes contribuyentes y después me quedo con la gente que me acepta y me hace sentir a gusto ${ }^{40}$. Sin saberlo, me ha ayudado a escapar a un cierto desasosiego referente a los extranjeros, que, en mi opinión, prevalecía bastante en esa época; los extranjeros eran raros, y eso hace inteligible que la gente tuviese sentimientos ambivalentes sobre ellos. En 1935, cuando Lynd empezó a ayudarme a encontrar un trabajo, parece que escribió a alguien con el que tenía correspondencia que yo no parecía muy judío; tengo la respuesta de éste, que escribió a Lynd que había escuchado cosas agradables sobre mí, pero que quería corregir a Lynd en este punto: «Lazarsfeld muestra claramente las marcas de su raza». En 1936, Hadley Cantril escribió a Lynd que estaba buscando un director de investigación que debía tener mi tipo de formación, pero que no fuera tan peculiarmente "disperso». Que esa palabra reflejaba una imagen de los extranjeros se desprende de esta alabanza, algo más tarde, después del primer estudio sobre radio, en el Journal of Applied Psychology ${ }^{41}$ : «Los dos [estudios] que me gustan especialmente - escribió - son los del señor director mismo, porque ilustran bellamente las tendencias que uno puede descubrir cuando las estadísticas se utilizan inteligentemente». De este modo - incluso en el momento en que él aprobó lo que yo quería hacer-, alguna noción de forastero trepador afloró allí.

Cuando incorporé en el proyecto sobre radio a T. W. Adorno, recién llegado de Alemania, tuve repetidamente que explicar que él no conocía todavía lo que iba a hacer. Tengo que volver sobre ello más tarde; pero ahora déjeseme decir que mi propia reacción fue característica. Tengo un memorándum de 7 de marzo de 1938, dirigido a Cantril y a Frank Stanton (los dos directores del proyecto), en el que yo informo de mi primera semana de experiencia con Adorno, donde escribí:

«[Adorno] parece exactamente lo que uno se imagina que es un profesor germano de mente ausente, y se siente tan extranjero que yo me

${ }^{40} \mathrm{Al}$ escribir lo anterior me doy cuenta de que esta costumbre la he sostenido durante los últimos veinte años, en los cuales he permanecido un tiempo considerable en varios países europeos. Mis contactos serios en estas ocasiones son — definitivamente- no con la gente de mi edad o los de estatus igual, sino con la gente más joven.

${ }^{41}$ Volumen 23 (1939). 
siento miembro de la Sociedad del Mayflower. Sin embargo, cuando uno comienza a hablar con él, tiene una enorme cantidad de ideas interesantes. Como todo recién llegado, intenta reformarlo todo, pero, si se le escucha, la mayoría de las cosas que dice tienen sentido».

Tan tarde como en 1941, cuando fui incorporado a la Universidad de Columbia, Samuel Stouffer tuvo que luchar con este duende. Escribió una carta (al comité de incorporaciones) que es uno de los más razonados documentos de apoyo que haya leído en los veintidós años desde que la recibí, donde se dice que:

"A pesar del hecho de que ha vivido en este país durante siete años o más, [Lazarsfeld] tiene una apariencia destacadamente extranjera y habla con un fuerte acento. Esto prejuzga a algunas personas contra él, y pienso que son además prejuicios porque sienten que hay algunas veces arrogancia en sus maneras. De hecho, Paul es uno de los hombres más modestos, pero tiene un modo fuertemente germánico de presentar un tema, que tiende a que alguna gente sienta que no es tanto el tema, sino la dificultad en seguirle que sugería. Pienso que esas críticas ocasionalmente tenían razón, pero yo puedo testificar desde la experiencia que está lleno de oro puro en un monte de grava».

Obviamente, Stouffer se sentía incómodo trayendo a colación el tema, y por eso al final se caricaturiza a sí mismo como un tipo de rudeza campestre.

Presento estos ejemplos para caracterizar el ambiente de ese período, ambiente notoriamente diferente del actual, en el que los intelectuales nacidos fuera son muchos en la vida profesional y académica ${ }^{42}$. Pero, a pesar de eso, nunca fui seriamente un estorbo, porque nunca se me ocurrió aspirar a un puesto universitario principal. Di por sentado que tendría que dar pasos similares a los dados en la creación del Centro de Investigación de Viena si quería encontrar un lugar para mí en los Estados Unidos.

Esto me lleva al segundo ejemplo de la noción de adaptación estructural. Cuando llegué a los Estados Unidos el problema de introducir —en la estruc-

${ }^{42}$ No hay que despreciar el hecho de que cada persona tiene características diferentes, y que algunas de ellas pueden alimentar un estereotipo. En la cita mencionada, Stouffer dice que algunas gentes tienen prejuicios contra mí. Tengo una carta de Craig en que quiere explicarme por qué no pudo ayudarme antes de salir de Pittsburgh: me ruega que no venga a los Estados Unidos porque tendría muchas dificultades personales. (La carta llegó a Europa cuando yo había vuelto a los Estados Unidos.) Relacionadas con esta (ciertamente sincera) expresión de amistad, hay frases como «La gente no se siente segura con usted... usted es demasiado grande todo el tiempo y nunca suficientemente modesto... usted parece haber hecho muchos amigos rápidos... Por eso yo soy un miserable».

Es obviamente imposible para mí juzgar la base concreta y amplia de esta reacción. Algo de lo que soy consciente es que, en el primer año, fui más bien rudo para estudiantes y ayudantes, a los que reprendí cuando no cumplían una tarea asignada. Quiero pensar que cambié de conducta al mismo tiempo que aprendí a comer con el tenedor en la mano derecha. 
tura de la Universidad - la investigación social empírica se hizo aparente. Era obvio que se necesitaba un nuevo tipo de Centro de investigación, aunque ninguno se había desarrollado satisfactoriamente ${ }^{43}$, a causa de la falta de gente cuya experiencia y carrera los hubiera preparado para crear y dirigir esos Centros. Dicho de otra manera, en la escena no había hombres institución ${ }^{44}$.

Siempre me ha interesado el tipo de hombres que desempeñan papeles importantes en las innovaciones académicas. En diferentes ocasiones he intentado mostrar que esas innovaciones con frecuencia resultan atractivas para gentes que pertenecen a dos mundos, pero que no se encuentran seguros en ninguno de ellos. Los mejores ejemplos históricos son Wihelm von Humboldt, que, como dependiente en Weimar, pertenecía a la aristocracia prusiana más baja, y que creó la Universidad de Berlín en 1807; el otro ejemplo es Guillaume Budé, que fue sirviente entre los humanistas franceses, pero que tuvo acceso a la Corte de Francisco I y dedicó su vida al desarrollo del Collège de France frente a la oposición anti-humanista de la Sorbonne (de 1515 a 1550).

$\mathrm{El}$ «hombre institución» es un caso especial de una noción sociológica bien conocida: el hombre marginal que forma parte de dos culturas diferentes. Vive bajo presiones cruzadas que le mueven en varias direcciones. De acuerdo con sus dotes y circunstancias externas puede llegar a ser un revolucionario, un surrealista, un criminal. En algunos casos, su marginalidad puede llegar a ser la fuerza directiva para impulsos institucionales; la institución que crea le ampara y, al mismo tiempo, le ayuda a cristalizar su propia identidad. En mi caso, había una convergencia general hacia la innovación institucional. Bajo circunstancias económicas adversas en Austria y la fuerte corriente de un incipiente anti-semitismo, una carrera académica normal se me presentaba como casi imposible. Cuando vine a los Estados Unidos, yo no era un individuo conocido - como alguno de los inmigrantes especialistas en Física- ni estaba conectado con un movimiento visible — como el psicoanálisis y los psicólogos de la Gestalt_- (El estatus de becario Rockefeller me ayudó en los comienzos; pero algún tiempo después tuve la experiencia de la transición desde un extranjero distinguido a un residente indeseable.) En lado positivo yo pertenecía, marginalmente, a un cierto número de áreas de conocimiento entre las cuales había que trazar puentes: ciencia social y matemática, intereses académicos y aplicados, perspectivas europeas y norteamericanas. Parece razonable pensar que esa configuración me podía llevar a una carrera en torno a una innovación institucional, más bien que enderezada directamente hacia una movilidad individual.

La forma que adoptó lo anterior fue la del papel de director de un Centro, un papel al que yo antes me había acercado y que trataré de diseñar en los dos

43 Describí y documenté uno de tales esfuerzos abortivos en la Universidad de Chicago en mi discurso como presidente de la ASA, referido antes, nota 28.

${ }_{44}$ Los historiadores — recordando el Gueux - entenderán la aceptación de un término que originalmente tuvo ribetes peyorativos. Todavía existe una diferencia entre el «hombre organización» y el "hombre institución». El primero se supone que pulula alrededor, mientras el segundo encuentra en la institución un campo creativo de autoexpresión. 
apartados que siguen: uno de los puntos (al que volveré tantas veces) consiste en la necesidad de este rol o papel de asumir riesgos razonables al intentar innovaciones fuera de lo corriente, sin entrar demasiado en conflicto con las normas vigentes. $Y$, en esta conexión, se acaba este apartado con la nota del riesgo que corrí viniendo aquí. Recordaré que fui a Viena a solicitar un visado de inmigrante sobre la base de la promesa de un puesto de trabajo en el Instituto de investigación de ventas al por menor de la Universidad de Pittsburgh. Al día siguiente de obtener mi visado recibí un cablegrama de Craig en que me decía que se iba de Pittsburgh porque había logrado el puesto de director de investigación de la Federación de ventas al por menor; mi puesto de trabajo dependía de la confirmación del sucesor de Craig. En cierto modo, pues, mi visado era de dudosa legalidad y, lo más importante, no tenía ningún trabajo esperándome en los Estados Unidos.

Había intentado informar a la Fundación Rockefeller de mi decisión de viajar a Pittsburgh. Sus regulaciones exigían volver a casa al completar el período de mi beca, pero a la vista de la situación de Austria podría con más seguridad contar con su comprensión de la situación. Sin embargo, no teniendo un trabajo garantizado dudaba muchísimo de que una fundación norteamericana cooperase además en un viaje que iba contra las regulaciones gubernamentales. Se necesitaba o un trabajo o un aval de apoyo de un ciudadano norteamericano.

Desde luego que recuerdo todos los detalles de los pocos días y noches durante los cuales mi mente se sobrepuso. Tenía todavía el dinero de un mes de la beca; tradicionalmente, los becarios europeos se gastaban el dinero del último mes viajando en Europa, como un tipo de descompresión, por así llamarlo. Y finalmente decidí no informar a nadie, y utilizar estos últimos 50 dólares en comprar un billete de tercera clase en un lento buque norteamericano. Y así llegué a Nueva York como el clásico inmigrante, sin un penique. Pocos días después comencé el trabajo en el Centro de Investigación de la Universidad de Newark.

\section{EL PROYECTO DE RADIO ROCKEFELLER-PRINCETON}

Empleé la mayor parte del curso académico 1936-37 en las tareas de ganar dinero, supervisar estudios y formar directivos en Newark.

Escuché una vez en primavera que la Fundación Rockefeller se hallaba dispuesta para realizar un gran proyecto para estudiar los efectos de la radio sobre la sociedad norteamericana. La revisión estaba a cargo de John Marshall, empleado de la Fundación, cuya formación era de historiador medieval. Se estaba buscando un director del proyecto, y el trabajo le había sido ofrecido a un cierto número de personas importantes. Yo estaba interesado en el puesto, pero no tenía modo de presentar mi candidatura. Tenía, de hecho, alguna experiencia previa en investigación de radio. En 1930-31, nuestro Centro de 
Viena había realizado una investigación a gran escala de los gustos de los oyentes de las radios austríacas ${ }^{45}$. Una de mis colegas jóvenes en el Departamento de Psicología, Herta Herzog, había redactado su tesis para la graduación académica bajo mi supervisión, replicando un estudio inglés anterior. Personas con diferentes preparaciones intelectuales se les solicitó que escucharan alguna cosa concreta en la radio; los cuestionarios se les distribuyeron, y en sus respuestas se pudo descubrir que las características sociales (y de otro tipo) de la audiencia pública se basaban en la voz y la dicción del que hablaba en la radio ${ }^{46}$.

En los años siguientes visité los Departamentos de investigación de las emisoras principales de radio, y establecí relaciones amistosas con Frank Stanton, entonces un joven miembro directivo de CBS (Columbia Broadcasting System). Supe que [Stanton] estaba en contacto con los planes de la Rockefeller, pero no lo conocía lo suficiente como para pedirle ayuda. Se dijo que quien propuso la idea fue Hadley Cantril, el cual, pocos años antes, había publicado un libro con Gordon Allport sobre psicología de la radio. Había conocido a Cantril en el primer período de mi beca, cuando visité Harvard, y me impresionó muchísimo. Sin embargo, nos habíamos visto muy poco y, en cualquier caso, hubiera sido embarazoso para mí abordarlo directamente.

Como en otros casos durante ese período, mi principal vía de comunicación era Robert $S$. Lynd. Cantril le escribió acerca de si tenía alguna sugerencia para la dirección: debería ser alguien de mi formación, y al mismo tiempo indicó que tenía reservas sobre mí personalmente. Lynd despejó las dudas de Cantril y me recomendó.

En julio de 1937 fui durante seis semanas a Europa para visitar a mis padres y atender algunos asuntos personales. Recibí un cablegrama de Cantril ofreciéndome la dirección y el más bien fabuloso salario de 7.000 dólares («dos años o posiblemente cuatro, sede central Princeton»). Contesté que estaba muy interesado, pero que tenía que plantear una serie de cuestiones, lo que haría inmediatamente en la correspondencia que seguiría. Escribí a Cantril una carta de dos páginas y media a doble espacio fechada el 8 de agosto de 1937. La carta de Cantril me urgía a hacerme cargo de la dirección, y explicaba el proyecto:

«... la Universidad de Princeton, más específicamente la Escuela de Asuntos Públicos e Internacionales, había concedido una dotación de 33.500 dólares anuales para un proyecto de dos años —o una dotación total de 67.000 dólares- . Todo ello para realizar un proyecto con Stanton y yo mismo diseñado para estudiar ciertos problemas en la investigación de la radio...».

45 El diseño de la muestra y el cuestionario eran muy nä̈vs, pero en los años siguientes nuestro estudio fue citado como el primero de su clase en Europa. No me sorprendería que hubiese sido anterior en fecha a los estudios semejantes en los Estados Unidos.

46 Herta Herzog, "Stimme und Persönalichkeit», Zeitzschrift für Psychologie, 130 (1933). 
La cantidad mencionada era ciertamente muy grande. El propósito sustantivo del proyecto se describía de la siguiente manera:

«Nuestra idea era tratar de determinar eventualmente el papel de la radio en las vidas de diferentes tipos de oyentes, el valor psicológico de la radio para la gente, y las diferentes razones por las que les gustaba la radio. La Fundación Rockefeller, a través de John Marshall, sentía que se trataba de un nuevo tipo de proyecto que preguntaba cuestiones de "porqués" hasta entonces objeto de poca atención».

La carta insistía en que la formulación del propósito era intencionalmente difusa. De manera que fuese posible realizar varias investigaciones bajo esos enunciados. Se puede ver en la siguiente cita una notable afinidad con la tradición de Viena; Cantril y su maestro Allport siempre habían estado atentos al trabajo de Charlotte Bühler. Otro elemento de la descripción fue destacar la importancia de los métodos:

«Pensábamos que ello requería de un trabajo preliminar sobre los métodos, es decir, los métodos que esparábamos que sirvieran eventualmente para nosotros o para otros al objeto de encontrar las respuestas finales de las preguntas que nos interesaban».

Esperaba encontrar una «respuesta final» típica del tono optimista del período. Visto desde ahora — después de treinta años de investigación en medios de comunicación masiva-, muchos de nosotros sentimos que estamos todavía justo en el comienzo. La carta de Cantril incluía la expectativa de que el proyecto continuara durante otro período de dos años, y en este punto al menos su confidencia estuvo justificada por los hechos después.

Desde mi punto de vista, el contenido del proyecto no era el asunto principal. Yo había creado el Centro de Investigación de Newark, y el asunto que me interesaba era cómo le iba a afectar la nueva propuesta. Por eso le expliqué primero a Cantril lo referente al Centro:

«Inventé el Centro de Investigación de Newark por dos razones. Quería dirigir una gran variedad de estudios, de manera que yo estaba seguro de que mi experiencia metodológica pudiera aumentar - y eso es, como usted sabe, mi principal interés en la investigación- Intentaba establecer grupos de estudiantes jóvenes que iban a ser educados en esta clase de procedimientos de investigación que intentaba desarrollar. Y éste es el primer punto — creo- en que vuestro proyecto sería espléndido. La radio es un tema alrededor del cual efectivamente se debería probar cualquier tipo de métodos de investigación que pudiera ser aplicado satisfactoriamente». 
He citado una declaración más bien larga porque proporciona una comprobación del informe retrospectivo que hice en el precedente apartado: la formulación que hice en ese momento poco difiere de mi actual punto de vista. Siguiendo con esta perspectiva de formación de personal investigador presenté dos preguntas a Cantril. La primera fue:

«¿... sería posible establecer al menos en parte de su proyecto de tal modo que se pudiera utilizar como un tipo de institución de formación?».

La segunda pregunta se dirigía al corazón de lo que concibo como la actitud central del «hombre institución». Le dije a Cantril que me sentía afectado al considerar el colapso del Centro de Newark, lo que sucedería probablemente si yo me ausentaba para dirigir el nuevo proyecto. He aquí cómo expresé mi sentimiento:

«Intento identificar todo lo que hago con una institución que pudiera después de algún tiempo adquirir la dignidad a la que yo mismo — por razones de destino y tal vez de personalidad- puedo trabajosamente aspirar».

El resto de mi carta argumentaba la solución que yo proponía: el proyecto Rockefeller debía ser administrado como tarea adicional del Centro de Newark. Teniendo en cuenta que el presupuesto de este estudio singular era más de tres veces el presupuesto total del Centro, no es sorprendente que Cantril considerase mi propuesta como más bien absurda. Me contestó con una carta que fue amistosa, complementaria y persuasiva. Pero en el tema crucial era bastante firme.

«Su sugerencia de vincular el Centro de Investigación de Newark - me temo- está fuera de lugar. Lamento que usted no obtuviera el dinero allí, pero ésta es una de esas convenciones norteamericanas un tanto absurdas para una "institución" y sería imposible llevarse el puesto de trabajo a cualquier parte».

A mi vuelta de Austria me puse en contacto con Cantril para negociar el aspecto institucional. Es algo característico del hombre institucional que está demasiado impresionado por la inviolabilidad de las reglas. No recuerdo los detalles de esta reunión, pero puedo reconstruirla: Cantril y Stanton necesitaban un director, y probablemente se daban cuenta de que me podía provocar alguna inquietud el que me propusieran, como punto de partida, que abandonara el Centro de Newark. En mi caso, Cantril finalmente se mostró dispuesto a cambiar de idea. Tengo una copia de la carta que escribió a Lynd el 9 de septiembre de 1937, en su residencia de verano, en que le explicaba este cambio. 
Leyendo esa carta de cuatro páginas a un espacio, incluso hoy me divierte el maquiavelismo que parece haberme atribuido (al menos lateralmente). Con toda probabilidad, Cantril no sintió que merecía la pena molestarme, una vez que se había reafirmado en que los intereses del proyecto y Princeton serían adecuadamente mantenidos a salvo. Las partes sustantivas del acuerdo, que marcan el cambio de tercio del resto de la historia, se las comuniqué a Lynd por extenso. Cantril estuvo de acuerdo, y escribió a Lynd:

"que el Centro de actividades del proyecto estaría en el Centro de Investigación de Newark y que se esperaba que fuera a Princeton sólo para reuniones incidentales. Además de mi presencia en Newark, estaba de acuerdo en que cualquier cantidad de dinero del proyecto que fuera asignada para investigación en un área urbana se podría gastar en Newark, lo que quiere decir que yo podía colocar algunas personas aquí para estudios especiales. Dicho en términos prácticos, todo el acuerdo significa que el Centro de Investigación tiene un nuevo trabajo enorme».

La responsabilidad de tener concentradas mis actividades personales en una sola institución identificable merece una breve digresión. Más tarde intenté persuadir a mis directores asociados para que adoptasen, en general, la misma política. En un memorándum a Cantril y Stanton, escrito el 8 de febrero de 1938, les insistí para que relacionaran sus "otras» actividades personalmente con la Oficina de Princeton de la Investigación de radio:

«Pienso que todos nosotros — hasta donde sea posible - debemos utilizar nuestras actividades prioritarias o aparte del proyecto para alimentar el proyecto mismo... Yo he utilizado precisamente todo en lo que haya trabajado en los años pasados, y les llamo radio ahora... Frank es una muy buena inversión desde el punto de vista del proyecto, porque todos los materiales y conexiones que pudo los puso a nuestra disposición. Estoy muy seguro de que el trabajo previo y presente de Had pudiera ser utilizado en la actualidad del mismo modo, si él estuviera de acuerdo conmigo en mi filosofía expresada aquí. Ello se publicará en el marco del proyecto en vez de en una revista».

Dadas las muchas responsabilidades de mis diez directores asociados —uno de ellos llegó a ser presidente de una fundación de investigación con un gran presupuesto y otro presidente de CBS (Columbia Broadcasting System)—, mi sugerencia fue aceptada con poco entusiasmo. Después, nada se dijo de esto ${ }^{47}$.

${ }^{47}$ Cuando Robert Merton se hizo cargo como asociado principal mío en el Columbia Bureau of Applied Social Research dio su aprobación a esta filosofía, y actuó de acuerdo con ella. Las condiciones bajo las que esa estrategia tiene sentido (tanto en el nivel joven como en el maduro) reclaman un análisis y debate ulteriores. No puedo hacer más que plantear el problema general. 
En el otoño de 1937, pues, se había producido la simbiosis entre las Universidades de Princeton y Newark. El lazo de unión se formalizó cuando fui nombrado Asociado de investigación en la Universidad de Princeton. La formulación abierta o liberal del programa Rockefeller me permitió hacer cualquier tipo de estudio específico, en la medida en que yo lo presentase con alguna conexión nominal con los problemas de la radio, y ello dio como resultado un cambio lento de la situación en su conjunto. Cada vez más, las dependencias centrales de Princeton para el estudio sobre radio pasaron a ser el marco principal de muchas actividades, y Newark sólo el lugar de localización física. Además, tenía sólo un pequeño equipo directivo, reunido accidentalmente, y por ello tenía que escribir yo mismo muchos de los primeros artículos. Para sortear este hecho me inventé un pseudónimo, Elias Smith, con el cual aparecieron tres o cuatro de los primeros estudios del proyecto. Pero ahora no sorprendería a nadie que considerase más importante publicitar la institución que ampliar mi lista personal de publicaciones ${ }^{48}$.

En la primavera de 1938 pudimos ver que a todos les afectaba (aunque tal vez fui el último en saberlo) el hecho de que la sede central de la investigación sobre la radio era mi principal base de operaciones y que había logrado una vida institucional. Aceptábamos ayudas externas y alcanzamos acuerdos formalizados con varias agencias de investigación para obtener datos para análisis secundarios. Esta autonomía funcional en aumento de la sede central corrió paralela con el declive de la Universidad de Newark, que poco después colapsó. Hacia el verano de 1938 - y resulta relevante quizás que no puedo recordar ninguno de los detalles - a Kingdon le pareció que podía utilizar nuestro espacio para mejores propósitos y me pidió que lo dejara. Por entonces, Edward Schuman era el gerente de nuestras operaciones. Nunca se me ocurrió que nos iríamos a Princeton; muchos de nuestros contactos de investigación se habían establecido en la ciudad de Nueva York. A Schuman se le encomendó que buscase un espacio conveniente en Nueva York, y en el otoño de 1938 la sede central de la Investigación sobre la radio se trasladó al número 14 de Union Square, donde alquilamos unas pocas habitaciones.

48 La historia de Elias Smith tuvo una secuencia que merece alguna atención por su localización histórica. Durante el período de McCarthy se me invitó por la UNESCO a una reunión en París. Recibí el certificado normal necesario para mi visado, el cual contenía la pregunta de si alguna vez había utilizado un pseudónimo. Sin pensarlo, interpreté la cuestión en un marco político y contesté "No». Me dieron mi certificado. No contesté a algunas preguntas específicas, y una de ellas decía que era conocido por la agencia que certificaba que yo había usado el pseudónimo Elias Smith, y que por qué lo negaba. Envié los títulos de los artículos que se publicaron con el pseudónimo, y fue suficiente para la agencia de certificados. Lo asombroso del caso es que alguna agencia federal había encontrado este pseudónimo en papeles de la investigación sobre la radio. Incidentalmente, de vez en cuando me preguntaron en Columbia algunas personas que querían saber cómo era Elias Smith. 


\section{LA SEDE DE LA INVESTIGACIÓN SOBRE RADIO- TRABAJO Y POLÍTICA}

La descripción detallada de las actividades de la sede de Princeton en el Proyecto de radio nos llevaría demasiado lejos de los fines de este ensayo. En su lugar enumeraré los hechos y observaciones que me influyeron en el trabajo que prosiguió en este país. En el próximo apartado trataré de aclarar las relaciones de las investigaciones entre Estados Unidos y Europa.

1. Cantril y Stanton, mis directores asociados, se reunían conmigo casi todas las semanas para planear y revisar los trabajos en curso. Ellos me permitieron completa libertad de decisión y me proporcionaron muchos contactos valiosos, y yo permanecí informado sobre todo mediante un flujo estable de memoranda. Las copias de muchas de estas notas están guardadas y otras se pueden encontrar en los archivos; pudiera ser valioso que alguna vez se analizaran estos documentos para alcanzar una imagen real del modo en que un director anterior del Centro hizo que los asuntos fuesen adelante. Intenté por todos los modos posibles adelantar y prevenir todas las dificultades posibles, y se me ocurrió el eslogan de que es más importante para un director preocuparse que trabajar. Además, yo era consciente de que, como inmigrante reciente, gran parte de la autoridad que yo tenía procedía de la buena voluntad de mis dos asociados, los cuales tenían raíces más profundas en la realidad norteamericana.

Cantril era correctamente estricto en la administración del presupuesto, puesto que él era el responsable ante la Universidad. No me fue fácil la vida (por así decirlo) con él, porque con frecuencia sobrepasaba el presupuesto de Princeton, seguro de que cubriría el déficit con ingresos de alguna otra fuente. En conjunto, funcionó muy bien, pero puede ser útil señalar aquí una debilidad en la imagen del académico ejecutivo, que yo había desarrollado. En tanto que yo controlaba las situaciones por mí mismo, yo fui capaz de equilibrar el presupuesto, aunque a menudo resolvía las cosas dejándome el pellejo. Pero en las situaciones en que no lograba hacer trampas o conseguir fondos adicionales, la cosa se ponía más complicada. Por ejemplo, después de dejar Viena, al obtener mi beca norteamericana, parece que se presentaron muchas dificultades financieras. Recibí muchas cartas, especialmente del matrimonio Bühler, protestando de las dificultades financieras que les había creado a ellos. Muchas de las cuestiones concretas planteadas en estas cartas no las puedo entender hoy en día; pero no me cabe la menor duda de que había dejado detrás de mí una situación más bien caótica, incluso si las sumas de referencia eran más bien pequeñas con los criterios actuales. En asuntos financieros la doctrina de los «riesgos razonables» puede entrañar problemas singulares ${ }^{49}$.

49 De modo parecido, en el momento en que transferí la dirección del Bureau de Columbia a mi sucesor, Charles Glock, habíamos acumulado un déficit moderado, que yo — como de cos- 
2. Mientras los presupuestos del proyecto, para aquella época, parecían muy grandes, pronto resultó que no alcanzaban para la recogida de una parte considerable del material primario. Los planes originarios — según los formularon Cantril y Stanton- asumieron que era necesario dedicar mucho tiempo a los experimentos de laboratorio, pero, tal vez por mi formación, los experimentos representaron un pequeño papel desde el momento en que fui nombrado director. Casi por necesidad, la mayor parte de los primeros trabajos se basaron en lo que más tarde llamé análisis secundario. De la empresa Gallup obtuvimos sondeos en que habían preguntado cuestiones comparativas sobre lectores de periódicos y oyentes de radios y, además, los analizaron. Una de las fuentes principales consistió en un rating de programas, que entonces sólo se utilizaba para comparar el poder de los diferentes diseños de varios programas; nosotros reanalizamos este material insistiendo en las diferencias sociales, utilizándolas como hacemos ahora con las letras A, B, C para describir el estatus socioeconómico de los entrevistados ${ }^{50}$.

$\mathrm{El}$ análisis secundario de los ratings de programas sirvió de puente para el concernimiento que ha permanecido en mí por la estratificación social. En un memorándum a mis directores asociados (8 de febrero de 1938), desarrollé una serie de temas que permanecieron como recurrentes en muchos trabajos posteriores:

«En un informe hecho por "Análisis Cooperativo de Radio” encontré reiteradamente que los grupos económicos muestran diferentes tendencias al escuchar u oír la radio. La escucha se eleva desde A hasta $\mathrm{C}$ y baja con el grupo C [aquí se insertaron las tablas]».

Puede parecer raro hoy que estas diferencias fueran entonces una sorpresa. A la buena manera vienesa, inmediatamente ofrecí algunas explicitaciones tentativas:

«Probablemente la reducción en los oyentes desde los grupos C hasta el A se debe a más educación y a más dinero para otras clases de entretenimiento en los grupos más altos. También pudiera ser que en el grupo C el espíritu familiar estuviese más desarrollado. La baja de oyentes desde $C$ hasta $D$ pudiera deberse a malas condiciones de vivienda que llevaban a la gente a salir fuera de su casa; además, hay muchos modos en que esta influencia puede funcionar — por ejemplo, por discordias familiares o formación de pandillas—».

tumbre - contaba con cubrir con fondos procedentes de futuros estudios. El cambio de dirección tuvo lugar con motivo de una revisión financiera, y la Universidad prefirió cubrir el déficit con recursos procedentes de los fondos generales, y de este modo se estableció desde entonces un sistema de contabilidad más estricto.

${ }^{50}$ Uno de nuestros primeros resultados fue un artículo de H. M. Beville, que estaba entonces en el equipo directivo de investigación de la NBC (National Broadcasting Company), titulado «The ABC"s of Radio Audiences», Public Opinion Quarterly, 4 (1940). 
Me interesa hoy que entonces fuera consciente de la continuidad de mi propio trabajo:

«La comparación sistemática puede producir resultados muy importantes. Estoy hablando de una experiencia concreta en otro campo. Cuando escribí mi libro sobre adolescentes y empleo no hice otra cosa durante meses que recoger cifras sobre lo que la gente elegía como vocación en toda Alemania y Austria. Parecían bastante tontos en sí mismos, pero ofrecieron pistas maravillosas cuando se compararon y se consideraron las circunstancias de su elección».

La primera "concordancia» había sido escrita diez años antes, pero en este memorándum todavía encontré «maravillosos» algunos de los resultados. $\mathrm{Y}$ todo ello remite a una política administrativa para la que he requerido el apoyo de mis asociados:

«Estoy profundamente convencido de que la investigación de los asuntos actuales todavía contiene una gran riqueza de información que tiene importantes implicaciones sociales. Por eso estoy tan preocupado por tener fuentes que continuamente escudriñan las agencias para obtener resultados que, desde luego, nosotros habremos examinado muy cuidadosamente».

Mi insistencia en este tipo de materiales ha tenido últimamente considerable influencia en mis propias publicaciones. La etapa austríaca de mi investigación requirió diversidad de técnicas aplicadas a muestras más bien pequeñas. Ahora me enfrentaba con la tarea de darle sentido a los datos que proceden de muestras grandes, con información relativamente escasa sobre cada entrevistado. Esto me llevó al análisis multivariable ${ }^{51}$.

También creció mi interés por los métodos de investigación cualitativa. Durante mucho tiempo sentí que en ese campo eran necesarias y también posibles explicaciones metodológicas. En la introducción al estudio de Komarovsky de familias desempleadas había escrito:

«El presente estudio... pretendía contribuir a un análisis más esmerado de estos procedimientos no-cuantitativos que muy frecuentemente se apoyan en la pereza del "sentido común". Se asume con mucha frecuencia que sólo los procedimientos cuantitativos pueden ser comunicados, mientras todos los otros procedimientos (intuición, comprensión) se tienen que dejar a la inspiración del estudioso y las exigencias del problema que se está tratando. Los métodos no-cuantitativos no pueden ser for-

51 El resumen más accesible es la entrada "Survey Analysis», en la nueva International Encyclopedia of the Social Sciences. 
mulados tan explícitamente como un cálculo matemático. Pero estos procedimientos, ahora arropados con términos ambiguos, necesitan ser descritos y normalizados en adelante».

Pero no sucedieron muchas cosas hasta que Cantril presentó un importante tipo de procedimiento dentro de las actividades del proyecto: sugirió que un número pequeño de entrevistas abiertas se realizara a oyentes que fueran fans de programas típicos de radio. Esta sugerencia la hizo suya Herta Herzog, que era miembro del equipo directivo desde los primeros años. El primer resultado (y más ampliamente citado) de este enfoque fue su discusión del entonces programa popular del Profesor Quiz ${ }^{52}$. Ella más tarde hizo un estudio similar de los oyentes de radionovelas diarias, en colaboración con T. W. Adorno, que apareció en la revista del grupo de Horkheimer que en esa época se publicaba en los Estados Unidos ${ }^{53}$.

La naturaleza, en gran medida cualitativa, de estos dos primeros estudios se llevó a cabo por dos grandes empresas, una después de la otra, donde se produjo un pequeño obstáculo estadístico que dio resultado. Uno de esos estudios fue The Invasion from Mars (La invasión desde Marte) ${ }^{54}$, y el otro el estudio de los bonos de guerra de Kate Smith —estudio que fue supervisado por Robert Merton y que constituye la base de su Mass Persuasion (1947)_. Los estudios que acabo de mencionar constituyen ejemplos de lo que más tarde se designó como «Estudios con la casa ardiendo». En ambos casos, llamé por teléfono a Stanton a la mañana siguiente del acontecimiento y proporcioné fondos del presupuesto de la investigación de CBS para el trabajo preliminar inmediato. En la actualidad la burocratización de las ayudas de investigación hace que tales improvisaciones resulten difíciles. Eso lo encuentro rechazable, y deseo que en los fondos urgentes para una investigación se puedan movilizar rápidamente, a medida que las demandas de la situación se pudieran satisfacer.

3. Durante este período, en alguna ocasión Harold Lasswell creó su bien conocida fórmula para la investigación de los medios de comunicación masiva: para investigar "quién» dice «qué» «a quién» con "qué efecto». Del análisis de contenido y de la audiencia (o público) tratan del segundo y tercer elemento de su fórmula. El estudio de los efectos —el cuarto elemento- ocupaba conti-

${ }^{52}$ Apareció como una monografía aparte, y también en Radio and the Printed Page (Nueva York, 1940), pp. 64-94.

53 Herta Herzog, "On Borrowed Experience», Studies in Philosophy and Social Science, 9 (1941), 65-95.

${ }^{54}$ Las primeras entrevistas sobre el programa de Orson Welles las resumió Herta Herzog en un memorándum a Stanton que se publicó después como contribución a la literatura y que se amplió más adelante como el largo estudio The Invasion from Mars, de Hadley CanTRIL, Hazel Gaudet y Herta Herzog (Princeton, 1940). Aunque en su momento esperaba que la doctora Herzog recibiese una cuota mayor del éxito de su trabajo imaginativo en ese estudio, no hay la menor duda de que el tipo de entrevista utilizado en este estudio se debió a la iniciativa de Cantril. 
nuamente mi cabeza, y lo expondré en la sección VIII, más adelante. El descuido del «quién» en el Proyecto de Princeton es notorio: nunca hicimos estudios sistemáticos de la clase que hoy se llamarían investigación de las organizaciones. No fui ciertamente un olvidadizo del problema. El estudio de la industria de la música popular lo abordé en un trabajo anterior; en su momento yo también solicité un resumen de estudios como los análisis de Leo Rosten sobre los corresponsales de Washington. Este trabajo lo realizó Alexander George, que más tarde fue un investigador distinguido de la Rand Corporation.

La encuesta de George formaba parte de un gran compendio sobre comunicación masiva. En otra sección se trataba del análisis de contenido, y más tarde apareció como libro bajo la autoridad de Bernard Berelson ${ }^{55}$. El estudio de Joseph Klapper sobre los efectos de los medios masivos, después publicado como un bien conocido libro ${ }^{56}$, inicialmente formaba también parte de esta empresa. Otra sección más se ocupó de las instituciones, que dio como resultado algunos estudios específicos; el más notable, una disertación sobre los sindicatos en el negocio de la comunicación.

En algún momento de 1939-40 nuestra política de publicaciones era ya muy conocida, y algunas personas me ofrecieron estudios que habían sido emprendidos con sus propios medios. Uno de estos planteamientos procedía del profesor de Ciencia Política en Harvard, Carl Friedrich. Había realizado un análisis descriptivo de las relaciones entre el Congreso, la Comisión federal de comunicaciones y la industria de la radio. El estudio se publicó después en el Political Science Quarterly y lo considero un ejemplo muy ajustado de análisis institucional, mostrando una percepción de un importante análisis institucional y proporcionando información de hechos significativos. Decliné incluir este estudio como una de nuestras publicaciones. Mi argumento fue que las pruebas empíricas eran demasiado anecdóticas y no estaban de acuerdo con la tradición cuantitativa de nuestro proyecto. Quiero aprovechar esta ocasión para expresar mi rechazo al profesor Friedrich. Hoy sospecho que tuve entonces una motivación más compleja característica de alguien que era responsable de una institución nueva y que abría caminos nuevos. El próximo apartado proporcionará el necesario trasfondo.

4. La investigación de las comunicaciones era por aquella época una empresa nueva, y pronuncié conferencias sobre ello a públicos de alto nivel, tales como la Asociación de radioescuchas y la Asociación de editores de periódicos norteamericanos. En esas oportunidades me enfrenté a un problema difícil: la relación con la industria. En una de estas conferencias — publicada después en The Journalism Quarterly ${ }^{57}$ — formulé la cuestión de la siguiente manera:

55 Bernard Berelson, Content Analysis in Communication Research (Glencoe, Ill., 1952).

56 The Effets of Mass Communication (Glencoe, Ill., 1952).

57 "Some Notes on the Relationship between Radio and Press», Journalism Quarterly, 18 (1941), 10-13. 
«Aquellos de nosotros - científicos sociales - que estamos especialmente interesados en la investigación de las comunicaciones dependemos de las empresas para la mayoría de nuestros datos. De hecho, la mayoría de los editores de periódicos y radios han sido muy generosos y cooperativos en este período reciente en que se ha desarrollado investigación de las comunicaciones como una clase de empresa conjunta de industrias y Universidades. Pero el personal universitario siempre tiene un cierto sentido de pies firmes: ¿en qué punto los colegas comerciales encuentran alguna conclusión necesaria demasiado fuerte para aceptarla, y hasta qué punto no nos darán las fuentes indispensables de fondos y datos?».

Finalmente, encontré una fórmula de compromiso. En la conferencia sobre «El papel de la crítica en la gerencia de los medios masivos» comencé diciendo que los medios masivos eran muy sensibles a las críticas de los intelectuales, y éstos demasiado estrictos en sus denuncias generales; debería haber un camino para hacer una crítica más útil y manejable para los que la formulan y para los que la reciben. Un modo efectivo de lograrlo sería el desarrollo de las funciones críticas, como una parte aceptada, de la formación y el trabajo cotidiano de cualquiera que estuviese conectado con los medios masivos:

«No sólo debieran ser los problemas de la crítica debatidos en conferencias como ésta, sino que también debieran ser el objeto de cursos sistemáticos de programas de formación. Los estudiantes y los investigadores debían llegar a pensar sobre la crítica como algo que se estudia sistemáticamente; deberían estar persuadidos para emprender exámenes críticos de los medios masivos y producir materiales responsables para la crítica. Si todo este campo se institucionalizara de esta manera, entonces habría menos emotividad relacionada con la crítica».

Hice esencialmente cuatro sugerencias, con vistas a las escuelas de periodismo. Primera, la "cruzada" es una función tradicional y aceptada para el periodista; se debería hacer un estudio más cuidadoso de cuáles cruzadas tienen éxito, cuáles fracasan, y por qué; además, hay que someter a consideración la misma cuestión de promover cruzadas. Mi segundo punto fue que los directivos de los medios masivos tenían que entender mejor que la crítica de sus actividades forma parte del credo liberal:

«Los liberales se sienten traicionados. Esperaban que el mayor tiempo y dinero por el que ellos luchaban debería ser canalizado en las orientaciones y actividades en las que ellos estaban interesados; en su lugar, los medios masivos eliminaban tales actividades y orientaciones. La situación de los liberales se parece mucho a la del muchacho de secundaria que - después de llevar semanas ahorrando- consigue bastante 
dinero para comprar una pulsera para su chica, y después se entera que ésta se ha marchado con otro muchacho para mostrar su linda y nueva baratija. Se puede entender bien por qué los liberales están furiosos, y quizás usted casi puede simpatizar con ellos».

Como tercer punto sugería más atención al soporte crítico que los medios masivos pueden darse entre sí. Puse de manifiesto que la mayoría de los periódicos tienen crítica de libros, pero se ofrece poco debate sobre los programas de radio. En este punto me referí también a la estrecha relación entre investigación de audiencias y crítica literaria. Finalmente —cuarto punto-, sugerí que tendríamos que tener alguna clase de informe periódico sobre los contenidos de los medios masivos, de manera que todas las críticas pudieran tener una base fáctica:

«Este país está con razón orgulloso de sus muchos servicios estadísticos. Pero nuestro registro social queda miserablemente rezagado cuando se trata de cuestiones culturales. La investigación social no está todavía lista para darnos información mensual sobre si la gente es feliz o desgraciada. Pero nada sería más fácil que establecer un servicio basado en técnicas de muestras sólidas que nos informasen periódicamente del contenido de los periódicos, revistas y programas de radio. Se trata sólo de desarrollar la motivación pertinente y promover la maquinaria apropiada».

En todos los trabajos del Centro de Princeton he intentado relacionar la investigación con debates públicos, pero generalmente a través de nuestro Centro, sirviendo de función mediadora. De este modo — por ejemplo—, servimos de canal para un proyecto del director progresista de la Comisión federal de las comunicaciones, Clifford Durr. Había éste encomendado a Charles Siepmann que idease algo sobre el modo en que esta Comisión pudiera trabajar mejor con niveles de radio más altos. Este encargo dio como resultado dos documentos: el «libro azul» de la Comisión, que promulgaba niveles de licencias más estrictos, y Radio: Second Chance, de Siepmann. A las dos publicaciones la industria reaccionó con un antagonismo violento, y yo persuadí a John Marshall, de la Fundación Rockefeller, para que concediera un presupuesto extraordinario para poder organizar una conferencia durante dos días entre la industria, la Comisión y universitarios prominentes en el campo de investigación para discutir los temas ${ }^{58}$. No salió mucho de allí, pero pienso que ello se debió en parte al inicio de la segunda guerra mundial, y la implicación de los Estados Unidos eclipsó el interés por esta clase de temas.

Justo antes de la guerra, la Comisión federal de las comunicaciones planteó

58 La minuta de esta conferencia todavía está disponible y pudiera alguna vez merecer un análisis más detallado. 
la cuestión de si a los periódicos se les podía permitir poseer una emisora de radio. Recibimos fondos para proporcionar tarjetas perforadas (de ordenador) sobre cada estación de radio, datos de la propiedad de las emisoras y el modo en que se producían los programas de noticias. Estos fondos los proporcionó un comité compuesto por todas las emisoras de radio propiedad de los periódicos. En su momento fue una fuente importante de ingresos para nosotros, pero puse como condición de nuestro trabajo que la Comisión (FCC) tendría acceso a todos nuestros datos. Mirando atrás, considero que probablemente el comité de radio-periódicos aceptó esta neutralidad porque se sabía que los periódicos que poseían emisoras de radio tomarían la precaución de no utilizar esos medios como recurso monopolístico contra los periódicos de la competencia, que no eran propietarios de emisoras de radio; éstos fueron ampliamente recompensados con los ingresos de un aumento de la publicidad, que no caían bajo la jurisdicción de la FCC.

5. Después de un año de existencia —en el otoño de 1938—, el proyecto se encontraba en una posición particular. Por un lado, mi política de «todos los huevos en la misma cesta» dio como resultado la colección de un gran número de materiales y un ambiente de trabajo entusiasta dentro de un equipo directivo pequeño pero prometedor. De otra parte, la «imagen» del Centro no era buena. Ningún tema central era visible, y empezamos a escuchar rumores de que gente importante se preguntaba si nosotros sabíamos a dónde íbamos.

Ciertamente, había que hacer algo. No había ningún estudio principal al que pudiera señalar; algo había que hacer para que fuera aceptable mi política de improvisación de las investigaciones guiada por los materiales disponibles y los intereses y contactos personales. Se me ocurrió que podía persuadir a una revista para que me permitiera participar como editor invitado en un número sobre la investigación de radio; mediante la redacción de una introducción general podría ser capaz de agrupar los diferentes estudios como algo que pareciera sistemático. Recuerdo intensamente que tanto Stanton como Cantril me dijeron que eso iba contra la tradición norteamericana de que ningún editor se permitiría a sí mismo ser desplazado por un editor invitado. (Sería útil comprobar si ése era el caso — ciertamente_ en ese momento; hoy en día los editores invitados no son raros en absoluto.) No me desanimé, en parte porque los editores invitados en Europa de las revistas científicas eran bien conocidos ${ }^{59}$. Buscando por los alrededores se me dijo que al editor de Journal of Applied Psychology pudiera llegar a agradarle un arreglo de ese tipo. Lo estuvo, y la norma que supuestamente existía se rompió. En febrero de 1939 apareció el primer número de la investigación, en mi condición de editor invitado ${ }^{60}$.

59 Ayudé a Charlotte Bühler cuando en 1931 fue editora invitada para estudios de niños en la principal revista de psicología general.

${ }^{60}$ Este episodio, que implica la noción de riesgo razonable, significa una cierta creencia optimista sobre la maleabilidad del entorno social. Un director de Centro no puede permitirse subestimar o ignorar opciones. 
Este asunto refleja bien la situación en que se encontraba el proyecto transcurrido un año. En la introducción intenté dibujar el nuevo campo de la investigación de radio. Desde el punto de vista de una política, en el sentido anterior, tenía tres tareas. Primera, tenía que convencer de que este recién llegado era tan bueno como los miembros más viejos de la familia de la psicología aplicada; esto lo definí como "el total de una suma de técnicas utilizadas por los psicólogos cuando se les llama para que colaboren con agencias autorizadas para realizar la introducción de principiantes en un área social específica». No fue difícil mostrar que, en este sentido, la investigación de radio era un área paralela razonable a la de la psicología industrial o educativa. Segunda, quería mostrar que algo nuevo se estaba desarrollando. Éste fue un movimiento desde los estudios descriptivos hasta el trabajo interpretativo más estricto. Seleccioné la siguiente formulación:

«No debemos sorprendernos si una disciplina de la “investigación de la acción” debe evolucionar alguna vez, haciendo visible más claramente la gran similitud metodológica de muchos estudios que ahora no están concretados porque han sido hechos bajo diferentes rúbricas, tales como criminología, investigación de mercados, prevención de accidentes».

Desde entonces he preferido la frase «estudio empírico de la acción» porque el término "investigación de la acción» había adquirido un significado diferente $^{61}$. Y finalmente, como siempre, intenté situar la nueva actividad en un contexto más amplio:

«El proyecto de la radio lleva ciertamente el sello del sistema social presente y, a su vez, produce cierto efecto sobre las instituciones sociales... El estudio de la radio puede incluso servir para un mejor entendimiento de algunos asuntos básicos de nuestra sociedad... Esos problemas reclaman para su estudio a sociólogos, economistas, antropólogos, y tienen al mismo tiempo su lado psicológico».

Mi predicción de que el nuevo campo pertenece parcialmente a otras ciencias sociales, incluyendo la Sociología, ya es ciertamente verdad.

Los contenidos del número monográfico reflejan mis esfuerzos por hacer que las improvisaciones del primer año aparecieran coherentes. El número se dividió en cinco secciones: 1) problemas de índices o tasas; 2) investigación de programas; 3) técnicas de cuestionarios; 4) investigación en diferentes campos de actividad; 5) informes de otras encuestas, comprendiendo bibliografía de la «investigación actual sobre radio en Universidades». En la sección segunda incluí algunos estudios hechos por otras personas. Uno de ellos era de Charles

${ }^{61}$ Cf. la sección en The Language of Social Research titulada "The Empirical Study of Action». 
Osgood —entonces en Dartmouth - y trataba de la separación de la atracción y el nombre de una marca al poner a prueba spots publicitarios. Otro era de Cantril y trataba del papel de lo que se sabía sobre la selección y gusto de los programas de radio. Éste fue un experimento bien diseñado en el que participaron varias emisoras de radio; fue claramente realizado para el proyecto en los planes anteriores a 1937. La sección cuarta da idea del material que utilizábamos procedente de esferas en apariencia no relacionadas. Procediendo de los casos de Komarovski-Newark, presentamos algunos ejemplos para poner de manifiesto la importancia de la radio para la gente desempleada y, puesto que la familia de Suchman poseía una compañía de taxis, ofrecimos nuestra ayuda para ver si la introducción reciente de los taxis con radio aumentaba los accidentes. Gerhard Wiebe escribió sobre los ratings de las canciones populares, y el venerable Elias Smith presentó dos artículos sobre construcción de índices. Los artículos identificados después con mi trabajo fueron «Interchangeability of Indices» y otro sobre entrevistas repetidas (o "panel»).

El número de la revista como operación de apoyo fue un éxito. El segundo año del proyecto trajo nuevos problemas y condujeron, a su vez, a la fase final de mi historia. Primero, sin embargo, hay otro aspecto especial de nuestras actividades que quiero explicar.

\section{EL CENTRO DE LA INVESTIGACIÓN DE RADIO- CONTACTOS CULTURALES}

1. En los primeros años del proyecto estaba todavía preocupado con establecer conexiones entre los enfoques de investigación europeos y norteamericanos. En el espítitu del presente volumen puede resultar provechoso recordar algunos de los primeros esfuerzos para combinar las dos tradiciones de investigación.

Poco después de que empezara el proyecto de Princeton organicé una cena de encuentro con varios psicoanalistas para obtener de ellos ideas sobre lo que debíamos prestar atención en nuestro programa. La reunión tuvo lugar el 16 de diciembre de 1937 y — según mis notas, que pueden no ser muy exactasparticiparon Karen Horney, Harry Stack Sullivan, John Dollard y Erich Fromm. Envié, junto con la invitación, una lista de las cuestiones (de dos páginas a un espacio) que les quería plantear. Entre ellas estaban las siguientes: ¿puede la teoría freudiana elucidar el valor de entretenimiento de la radio y dar cuenta de programas especialmente populares? ¿Puede el método psicoanalítico de asociación libre ser utilizado en nuestro estudio sobre los radioyentes? Al desarrollar tipos de radioyentes, ¿habrá que volver a las experiencias primeras de los niños? ¿Podría la teoría del desarrollo psicoanalítico clarificar el papel de la radio en diferentes edades? La lista de preguntas concluía con el siguiente parágrafo: 
«Estoy seguro que en muchos casos que ustedes han tratado la radio estaba algo conectada con los problemas de sus pacientes. Sería muy útil para nosotros que ustedes pudieran recordar ejemplos de esta clase y decirnos algo sobre ello en nuestra reunión. Pensamos que ustedes podrían haber observado situaciones e incidentes que están más allá de nuestros métodos experimentales usuales».

Había tenido una reunión preliminar con Fromm, al que di la información necesaria para la declaración inicial que él hizo en la cena; ha sobrevivido un resumen de seis páginas de esta declaración.

Yo no había tenido ninguna relación especial con el psicoanálisis. Este episodio formaba parte de una responsabilidad especial por combinar los enfoques humanísticos y cuantitativos. Después de esa época la convergencia de la investigación social con el estudio de casos psicoanalítico es más conocida. Sin embargo, en 1937 nuestro empeño era probablemente muy nuevo. Sería necesario estudiar las minutas con más detalle para decidir si la reunión sirvió para aportar ideas interesantes.

2. Otra preocupación de este tipo fue el enfoque histórico. Cuando presenté a la Fundación Rockefeller mi primer informe de progresos, en 1939, puse de manifiesto que los esfuerzos para calibrar los efectos de la radio sobre la sociedad norteamericana, quince años después de que este nuevo medio hubiese aparecido, cuando se estimaba que era una empresa más bien azarosa. Para recalcar este punto sugerí un paralelo con un profesor que en 1500 pudiera haber sido interrogado sobre los efectos de la imprenta en la sociedad medieval. Después de mucho estudio empírico cuidadoso, podría haber contestado convincentemente que la imprenta no había tenido demasiado efecto:

«Primero, la imprenta sería tan cara que no podría competir con las copias hechas por monjes en un monasterio. Además, difícilmente la gente sabía leer, de manera que ¿cuál era la ventaja de ser capaz de hacer grandes cantidades de ejemplares? Entonces, también, la religión era el único problema que realmente importaba, pero la cuestión de la religión versaba sobre el púlpito, o el pensamiento privado de los individuos; no se pensaba en la imprenta. Y así por todas estas razones es claro que la imprenta no tiene que tener ninguna influencia sobre la sociedad, y esto cerraba la cuestión en $1500 »$.

Durante muchos años he dado clases sobre medios masivos de comunicación en la sociedad moderna. Una de estas clases se ha guardado porque finalmente fue una conferencia en la Fundación Borah ofrecida en Moscú, Idaho, en 1954; tiene una sección más bien extensiva de «retrospectiva histórica». Contenía una idea que he solido reiterar ${ }^{62}$ :

62 Como director del Centro tanto como profesor seguí desarrollando y compartiendo esa fórmula durante muchos años: cité entonces a partir de publicaciones accesibles sus datos, aun- 
«En tiempos de la revolución norteamericana había una simple relación de dos lados. En un lado estaban los ciudadanos; en el otro, el gobierno. Cualquiera que tuviese teorías políticas o un interés en las actividades políticas, o era un editor presente o potencial, de manera que compartía los intereses comunes con los otros ciudadanos. El ciudadano y el editor luchaban juntos por su libertad para criticar al gobierno. Sin embargo, en el último siglo la situación se ha complicado mucho más. La relación simple de dos lados ha sido reemplazada por una estructura compleja de tres esquinas. Los ciudadanos todavía representan una esquina, el gobierno también otra, pero ahora hay una industria de las comunicaciones. Esto lleva a alianzas complicadas y en ocasiones sorprendentes. Ocasionalmente los ciudadanos forman una alianza con la industria contra el gobierno; a veces, con el gobierno contra la industria; otras veces, se encuentran a si mismos con una alianza entre el gobierno y la industria. Muchas cuestiones sobre los medios masivos se pueden contestar si este desarrollo desde la relación de los dos lados hasta la de las tres esquinas se sostiene en la cabeza; la confusión se produce si las tendencias históricas se pierden de vista» ${ }^{63}$ (las cursivas se ponen ahora).

La idea de la estrategia latente es de nuevo pertinente. Este tipo de análisis histórico me parece útil para los problemas de política debatidos antes (sección VII). Subrayando que los temas controvertidos son eternos, pero al mismo tiempo variables en sus implicaciones, me pude mantener en el manejo del Centro entre el purista intelectual y político y una industria de la cual deseaba cooperación sin tener que "venderse».

Al mismo tiempo, mi interés histórico era bastante auténtico y permaneció como rasgo característico de mis actividades. Cuando el debate sobre la cultura de masas era particularmente recio, patrociné el trabajo de Leo Lowenthal sobre la historia de la crítica de los medios masivos ${ }^{64}$. Unos años después, cuando era presidente de la Asociación Norteamericana de Investigación de la Opinión Pública, mi declaración versó sobre «El historiador y los sondeos», tema que ha seguido siendo un punto de discusión ${ }^{65}$. Y de vez en cuando he

que en ciertos casos con rezago respecto del período en el que se originaron y en que los situé en este ensayo.

${ }^{63}$ Paul F. Lazarsfeld, "Mass Media of Communication in Modern Society", Borah Foundation Lectures 1954 (Moscú, Idaho, 1954).

${ }^{64}$ Leo Lowenthal, "An Historical Preface to the Popular Culture Debate», en Norman Jacobs (ed.), Culture for the Millions (Princeton, N.J., 1959). El libro es un informe sobre un simposio organizado conjuntamente por la Academia de Artes y Ciencias y el Instituto Tamiment. Participé como presidente de la sesión dedicada al libro y subrayé una vez más el papel constructivo de la crítica.

65 "The Obligation of the 1950 Pollsters to the 1984 Historians», 1984, Public Opinion Quarterly, 14 (1950), 618-663. Para un revisión puesta al día, véase Lee BENSON, "An Approche to the Scientific Study to the Past Public Opinion», Public Opinion Quarterly, 31 (1967), 522-568. 
publicado ensayos sobre esos asuntos como la historia de la cuantificación, la formación de conceptos y el estudio empírico de la acción ${ }^{66}$.

3. En el campo de la música se produjo otra convergencia con las humanidades; ello merece un debate más detallado. Siempre he estado interesado en la música y cuando me nombraron director del proyecto de Princeton inmediatamente organicé una sección especial de música. Los dos primeros estudios formaron parte del programa general. Se comenzó con un serio estudio institucional sobre la industria de la música popular, que, hasta entonces, no había recibido la atención que se merecía. Al mismo tiempo, iniciamos una encuesta para perfilar el efecto de las transmisiones de la Nueva York City (WNYC), una de las primeras estaciones de radio, con el objeto de transmitir grandes cantidades de música clásica. Esto era anterior a la popularidad de los discos, y el interés en la música seria era bastante escaso; deseábamos saber si la WNYC contribuiría a la difusión de esa música ${ }^{67}$.

Pero no tenía más planes para esta sección. Tenía conocimiento del trabajo de T. W. Adorno sobre sociología de la música. En la actualidad, Adorno es una figura principal de la Sociología alemana, y representa un lado de un largo debate entre dos posiciones: a menudo designadas como sociología crítica y sociología positivista ${ }^{68}$. Yo era consciente de los rasgos controvertidos del trabajo de Adorno, pero me intrigaron sus escritos sobre el papel "contradictorio" de la música en nuestra sociedad ${ }^{69}$. Consideré como un desafío el tratar de inducir a Adorno a que intentara relacionar sus ideas con la investigación empírica. Además, sentía gratitud al grupo de Frankfurt dirigido por Horkheimer, del que Adorno era miembro; ellos habían ayudado al Centro de Newark, y yo sabía que querían traer a Adorno a este país. Por eso le invité para que fuera director a tiempo parcial de la sección de música de nuestro proyecto. Para proporcionar un experto en datos empíricos designé al mismo tiempo a un anterior alumno de Stanton, llamado Gehard Wiebe, que era un buen músico de jazz, con un doctorado en psicología. Éste y Adorno - esperaba yo- desarrollarían una convergencia de la teoría europea y el empirismo norteamericano.

${ }_{66}$ "Concepts, Theory and Explanation in the Behavioral Sciencies», en Gordon J. DiRenzo (ed.), Concept Formation and Measurement in the Behavioral Sciencies (Nueva York, 1966).

${ }^{67}$ Edward Suchman, «Invitation to Music», en Duncan y MacDougald, Jr., "The Popular Music Industry», en Paul F. Lazarsfeld y Frank Stanton (eds.), Radio Research 1941 (Nueva York, 1941).

${ }^{68}$ La primera fórmula de la que soy consciente proviene de Max HorKHEIMER. Esto se puede ver en el vol. 6 (1937) de la Zeitschrift für Sozialforschung: "Teoría crítica y tradicional», pp. 245-295, y "Filosofía y teoría crítica», pp. 625-631. Presentaciones contemporáneas de estas dos posiciones se encuentran en los dos artículos siguientes: Hans AlberT, «Der Mythos der totalen Vernunf. Dialektische Ansprüche im Lichte undialekeinen Kritik», Kölner Zeitschrift, 16, h. 2 (1964), 225-256; Jürgen HABERMAS, "Gegen einen positivischen halbierten Rationalismus», Kölner Zeitschrift, 16, h. 4 (1964), 635-659.

69 "Zur Geseeschaftlichen Lage der Musik», Zeitschrift für Sozialforschung, I, (1932), 103 y ss., 356 y ss. 
El decurso efectivo de los acontecimientos tomó un rumbo bastante diferente de lo esperado. La cooperación entre estos dos hombres se hizo difícil, y Adorno llegó a ser el símbolo de un problema más general. En unos cuantos «memos» escritos en la primavera de 1938 y dirigidos a mis directores asociados les di cuenta de la brillantez e importancia de las ideas de Adorno. Esto me parece necesario, puesto que sus entrevistas a personas de la industria de la radio produjeron quejas sobre cuestiones que contenían prejuicios y respuestas distorsionadas. Éste fue el resultado - expliqué- de los malos entendidos comunes de encuentros de este tipo. Para estresar más la situación le pregunté a Adorno que resumiera sus ideas en un memorándum que planeaba distribuir entre varios expertos para asegurar una base más amplia de apoyo a su trabajo. En junio de 1938, Adorno nos dirigió un memorándum de 160 páginas a un espacio titulado "Música y radio». Pero me pareció que la distribución de este texto haría la situación más difícil porque en inglés su escrito tenía la misma capacidad de molestar e irse por las ramas que tenía el texto en alemán. La noción de "fetiche» - como pudiera esperarse de un neomarxista - representaba un papel central. Proponía utilizarla

«siempre que cualquier actividad humana o cualquier producto de esa actividad quede alienado de los hombres hasta el punto de que no puedan — por así decirlo— reconocerse a sí mismos en ellas. Es así como los hombres lo veneran como algo cuyo valor está completamente divorciado de la actividad humana que lo abarca y de las funciones que efectivamente ejerce sobre otras actividades humanas. En cualquier caso (por ejemplo, en el caso de las "estrellas" que se han convertido en fetiches), ello está muy cerca del concepto de sugestión por el que la gente venera algo sin saber exactamente por qué... y sin estar inmediatamente relacionado con ello. La dimensión de los fetiches es — sin embargo- más grande que la de la sugestión y la propaganda. La sociedad actual está preparada para echar fuera los efectos de los aparatos instalados porque el valor de los aparatos es el valor fundamental que reconoce, incluso en casos en que el valor no está representado en ellos por ninguna propaganda especial para la sugestión».

La teoría crítica menosprecia el uso de definiciones; pero, ciertamente, Adorno era capaz de ofrecer ejemplos vívidos que ayudaban a captar lo que él tenía en mente, como se puede ver en otro párrafo:

«Pero la fabricación de fetiches musicales va más allá de los límites de lo que se llaman "estrellas" que, en la superficie, parecen ser responsables de los rasgos mencionados aquí. El fetiche efectivamente toma posesión de prácticamente todas las categorías musicales en la radio. La música en la radio se concibe como propiedad privada. Por ejemplo, citemos el culto a instrumentos musicales famosos, o bien los violines 
"Stradivarios" (aunque el promedio de los oyentes no es en absoluto capaz de cualquier distinción entre "Stra" y cualquier otro violín bueno ordinario); los pianos que alguna vez tocó gente famosa como Chopin o Richard Wagner; o - para acabar pero no es de menor importanciaciertos elementos de la composición sobredimensionados por la técnica de la radio, y que al mismo tiempo parecen presentar la música como un mueble».

Desde el punto de vista del proyecto, el problema principal consistía en ver si el fenómeno del fetichismo podía ser descrito mediante el enfoque directo de una muestra de radioescuchas. (El mismo tema existe cuando la noción estructural de anomia, de Durkheim, se pone en paralelo con una distribución de características individuales que ahora con frecuencia se llama "anomia».) Adorno y yo estuvimos de acuerdo en que él debía establecer una tipología más discriminante; sólo entonces el cuestionario podría conducir a una distribución cuantitativa de diferentes tipos de oyentes de música. Pero no se desarrolló ningún indicador para una tipología porque la orientación que él dio difícilmente se podía traducir en términos empíricos. Así, por ejemplo, uno de los tipos fue descrito como sigue:

«A veces la música produce el efecto de liberar deseos sexuales ocultos. Éste parece ser particularmente el caso cuando una mujer contempla la música como una especie de tipo de su pareja masculina, a la que ellos se someten sin identificarse nunca ellos mismos con la música. Es el tipo de actitud que está indicado por las lágrimas. Las lágrimas del amateur cuando escucha música (el músico prácticamente nunca llorará) es una de las tareas futuras del análisis del lado emocional de la música».

Le escribí a Adorno una detallada crítica de su memorándum y, finalmente, llegamos al acuerdo de que él escribiría un documento mucho más breve que pudiera ser debatido después en una reunión con varios expertos. La reunión tuvo lugar durante el invierno de 1938/39, pero no fue provechosa. John Marshall estaba presente y probablemente sintió que mis esfuerzos por traer el tipo de investigación crítica de Adorno al campo de las comunicaciones eran un fracaso. La renovación de la ayuda de la Rockefeller en el otoño de 1939 no proporcionó ningún presupuesto para el proyecto sobre música.

Nunca me arrepentí de haber invitado a Adorno para que se uniera al proyecto. Poco después de que él lo dejara, el grupo de Horkheimer dedicó un número de su revista al problema de las comunicaciones masivas modernas, $\mathrm{y}$ allí se publicó un ensayo mío tratando de explicar el «enfoque crítico» de modo acorde con un público norteamericano, y los caminos que ejemplificaban la posición básica que pudiera conducir a nuevas ideas de investigación ${ }^{70}$.

70 "Administrative and Critical Communication Research", Studies in Philosophy and Social Science, 9 (1941), 2-16. 
Incluso traté de enumerar «las operaciones en las que se puede dividir la investigación crítica de las comunicaciones». Utilicé comparaciones para hacer ver la idea principal: los movimientos de consumidores luchan contra anuncios equívocos y algunos economistas deploran su rusticidad; pero el enfoque crítico piensa que cualquier clase de promoción comercial impide que la gente desarrolle sus propios niveles de criterios de juicio. Acabé el artículo con las siguientes frases:

«[El] Centro de la investigación de radio había colaborado en este tema porque sintió que sólo una concepción muy universal de la tarea de investigar puede llevar a resultados evaluables... El autor cuyos intereses y deberes laborales se encuentran en el campo de la investigación administrativa, quisiera expresar su convicción de que hay aquí un tipo de enfoque que - si eso se incluyera en la corriente general de la investigación de las comunicaciones- podría contribuir mucho, en tanto que problemas desafiantes y nuevos conceptos útiles, en la interpretación de lo conocido y en la búsqueda de nuevos datos».

El fracaso de esta esperanza en el proyecto de Princeton había dejado en mi mente una cuestión que debo reconocer que me perturbaba. Después de la guerra, Adorno fue un miembro activo del grupo de Berkeley que realizó $L a$ personalidad autoritaria. Su concepto básico sobre el carácter fascista se desarrolló por Adorno y fue ciertamente no menos especulativo que el que él escribió para nosotros; no obstante, sus colegas de California fueron capaces de convertir su idea en la famosa Escala-F. Tenía yo un sentimiento incómodo de que mis deberes en las diferentes secciones del proyecto de Princeton me habían impedido dedicar el tiempo y la atención necesarios para lograr la finalidad para la que yo había comprometido a Adorno originalmente. Y ocurrió que el único escrito que pudimos publicar fue un artículo sobre la radio sinfónica; él mismo más tarde publicó una versión abreviada del memorándum mencionado antes ${ }^{71}$.

Me produjo algún bienestar el hecho de que todos los contactos con los expertos germanos sobre cuestiones de estética fallaron. Rudolf Arnheim ha escrito un ensayo sensitivo sobre el cine como forma de arte; le encomendé analizar los guiones de cincuenta seriales diarios, lo que hizo brillantemente. Una de sus observaciones ha sido citada a menudo desde entonces: las llamadas "óperas de sopas», que consistían en historias continuas en las que las familias se encuentran a sí mismas con problemas que triunfan al resolverlos para caer inmediatamente en nuevos problemas, que se transmiten durante el día y fueron escuchadas principalmente por amas de casa. Arnheim notificó -y desarrolló las implicaciones del hecho- que los problemas siempre los causa-

T. W. Adorno, «The Radio Symphony», en Lazarsfeld y Stanton (eds.), Radio Research 1941: «On Popular Music», Studies in Philosophy and Social Sciences, 9 (1941). 
ban hombres y las soluciones las proporcionaban mujeres. Recuerdo la colaboración con él como útil para el proyecto ${ }^{72}$.

Cuando el Centro se mudó a Columbia y podía contar con una situación permanente, la Universidad se convirtió en mi grupo de referencia y la preocupación por los contactos culturales se debilitó. Es muy probable que en muchos otros aspectos el componente norteamericano en mi posición marginal se hizo cada vez más fuerte. Pero, obviamente, mi preocupación por la relación entre las dos tradiciones de las ciencias sociales nunca disminuyó. En 1958 fui el relator sobre metodología en la Convención Stresa de la Asociación Internacional de Sociología (ISA). El tema principal de mi informe versó sobre la manera de evitar malos entendimientos entre los sociólogos europeos y norteamericanos.

\section{DESDE PRINCETON HASTA COLUMBIA}

En ciertos aspectos, el segundo año académico del Centro de Princeton de la investigación de radio (1938/1939) fue similar al primero, pero se hizo visible un cierto grado de consolidación. Los artículos de este período se publicaron en el segundo número del Journal of Applied Psychology, con el título "Avances en la investigación de radio»" En la introducción escribí como editor invitado, y señalé:

«Las dos tendencias principales en la investigación de radio se han hecho noticiosas. Los estudios sobre los efectos de la radio han pasado al primer plano; los materiales recogidos con fines comerciales son más fácilmente accesibles para análisis científicos; y las áreas relacionadas, tales como las áreas de lectura, se desarrollan tan rápidamente que la disciplina de la investigación general sobre las comunicaciones parece que se está elaborando».

La referencia a los estudios de los medios masivos impresos merece que le prestemos algún comentario. Las cifras de circulación de revistas parecen pequeñas comparadas con el tamaño de las audiencias de radio, pero cada ejemplar de una revista se lee por varias personas; las cifras de lectura son comparables a los rating de la audiencia. Desde nuestro punto de vista, esto significó una nueva zona del análisis secundario: el estudio de la estructura de las "audiencias» (o "públicos») de las revistas para obtener

72 Rudolf Arnheim, «The World of the Daytime Serial», en Paul F. Lazarsfeld y Frank Stanton (eds.), Radio Research 1942-43 (Nueva York, 1944).

${ }^{73}$ Este número apareció en diciembre de 1940 porque el editor responsable no quiso que dos temas de radio se publicaran juntos; sin embargo, los artículos mismos provienen de la época del proyecto de Union Square. 
conclusiones de una comparación con la distribución de los oyentes de la radio $^{74}$.

Pasaron al primer plano dos actividades: una, la que más tarde se llamó «Analizador de Programas Lazarsfeld-Stanton». Siempre me había interesado la música popular, y cuando todavía estaba en Viena diseñé una técnica mediante la cual se pudiera relacionar la estructura musical de una canción con las reacciones emocionales de los oyentes. Ahora, con el Proyecto de Princeton era posible ampliar la idea a todas las clases de programas de radio, y también a las películas. Publicamos una serie de estudios técnicos de este analizador de programas $^{75}$, pero resultaba un procedimiento demasiado caro para que lo utilizáramos nosotros. Era dudoso que lo pudiésemos patentar, pero dos grupos comerciales, CBS y la compañía de publicidad MacCann-Erikson, nos abonaron un canon por el derecho de utilizar el invento en sus propios Departamentos de investigación. Desde entonces, el analizador de programas ha encontrado toda una variedad de aplicaciones comerciales. Espero que algún día toda esta idea se pueda convertir de nuevo en un objeto de indagación académica.

En tanto que la importancia crítica del analizador de programas se desvaneció después de cierto tiempo, los estudios con la técnica panel se convirtieron cada vez más centrales en nuestras actividades. Mirando los primeros archivos del proyecto Princeton me sorprendió ver lo pronto que empezamos con entrevistas repetidas en el estudio de los efectos de la radio. Aunque no puedo encontrar ahora informes completos sobre el tema ${ }^{76}$, existen memoriales a los directivos y a los directores asociados desde 1938 que indican que gastamos una gran parte del dinero de nuestro proyecto en pequeños estudios piloto rebuscando los efectos de varias campañas locales en Nueva Jersey.

Administrativamente, la principal innovación en la última parte del período de Princeton consistió en una serie de becas que John Marshall estableció para estudiantes graduados que deseaban especializarse en investigación de las comunicaciones; integramos el trabajo de estos becarios en nuestro programa general, y yo me encargué de supervisar su trabajo. El criterio fue asignarlos a actividades concretas de los medios, tales como un programa de asuntos públicos que procedía de la Universidad de Chicago o a una estación de radio para una población principalmente rural y dirigida por la Universidad Estatal de Iowa. Un cierto número de estos estudios especializados se publicaron por la

${ }^{74}$ Era miembro del programa de investigación sobre la audiencia de las revistas. Estaba la revista guiada con mano experta por Neal DuBois, entonces director de investigación de la revista Life. La mayoría de las principales revistas estaban representadas en el grupo. Un sumario de los muchos estudios de audiencias hechos en esa época se puede encontrar en mi artículo "Communications Research and the Social Psychologist», en Wayne Dennis (ed.), Current Trends in Social Psychology (Pittdburh, 1948).

75 Véase, por ejemplo, Tore HollonQuist y Edward Suchman, «Listening to the Listener», y Adolf StURmnthal y Alberta CurTis, "Program Analyzer Tests of Two Educational Films", ambos en Lazarsfeld y Stanton, Radio Research 1942-43.

${ }^{76}$ La única excepción la representa un trabajo de la dirección (1939), de Hazel GAUDET, que después se incluyó en The Language of Social Research. 
Comisión federal de la radio educativa. Pudiera ser bueno rastrear el origen y desaparición de esa Comisión como parte de la historia de los primeros esfuerzos sobre radio y televisión educativas.

Hacia la primavera de 1939, el problema de la renovación de la ayuda de la Rockefeller era urgente. John Marshall, que había seguido de cerca nuestro trabajo, estaba a favor de ello. Convocó un comité de revisión que incluía a Charles Siepmann, Harold Lasswell, Robert Lynd y Lyman Bryson: dieron un veredicto favorable ${ }^{77}$, pero para los menos directamente informados sobre los detalles, la falta de un tema central después de dos años parece que les produjo una pobre impresión. Durante un viaje a Iowa recibí un cablegrama de Frank Marshall en que me indicaba que la Fundación pedía una evidencia más sólida de resultados antes de aprobar nuestra petición.

El problema para nosotros era repasar los materiales disponibles y seleccionar un tema en torno al cual se pudiera organizar una gran parte de esos materiales. Por una serie de razones, la comparación entre la radio y los medios impresos pareció la elección más prometedora. Así nació Radio and the Printed Page (1940), libro que desempeñó un papel considerable en la consolidación del campo de la investigación de las comunicaciones. Constituyó una tarea extenuante componer el manuscrito en un corto período de tiempo; trabajábamos noche y día literalmente, en turnos, para concluirlo. Movilicé todos los recursos imaginables, y recuerdo con especial gratitud la ayuda de Lloyd Free, que se ofreció voluntario al vernos en este trance. Teníamos datos de sondeos de Gallup sobre preferencias en los informes de noticias, pero no habían sido adecuadamente analizadas, y por eso pedí a Samuel Stouffer que viniera a Nueva York a supervisar esta parte del trabajo. Por su iniciativa se incorporó un inteligente análisis de cifras sobre circulación de periódicos para establecer el posible efecto de la radio; las dos secciones con que él contribuyó al libro ahora se incluyen propiamente en sus artículos seleccionados ${ }^{78}$.

Presenté el informe en la mañana del final del plazo, que - si no recuerdo mal- era el 1 de julio de 1939. A John Marshall le satisfizo y lo consideró como base adecuada para proponer oficialmente la continuación de nuestro proyecto a la Fundación ${ }^{79}$.

Entretanto se presentaron dificultades internas entre Cantril y yo. Durante las negociaciones con la Fundación Rockefeller para la renovación de la ayuda,

77 Encuentro en los archivos un cierto número de memorandos en los que sugiero a los directores asociados la estrategia adecuada que debe seguirse y el papel que ellos deben jugar -buen ejemplo de la conducta típica de un «director en apuros».

78 Social Research to Test Ideas (Nueva York, 1962).

79 La cuestión de las publicaciones fue algo engorroso porque entonces el mercado - que ahora proporciona libros para numerosos cursos sobre investigación de las comunicaciones masivas - no existía. Robert Lynd urdió la estrategia que triunfó: un amigo de él escribió una historia para el Reader's Digest procedente del manuscrito. Sobre esta base, Duell, Sloan y Pearce publicaron el libro. A partir de entonces no ha habido dificultad para encontrar salidas a nuestros estudios. 
quedó claro que había que tomar una decisión administrativa. $\mathrm{O}$ el proyecto seguiría en Princeton con Cantril como figura principal, pero con un nuevo director, o, si yo permanecía, el proyecto tendría que buscar otra base institucional. La Fundación naturalmente se fijó en Stanton como tercer miembro para arbitrar la situación; por el resultado deduje que Stanton se inclinó por mí. Lynd persuadió al presidente Dodds de Princeton para que dejara el proyecto. En el otoño de 1939, el Centro de Investigación de Radio se trasladó a la Universidad de Columbia, y al mismo tiempo fui nombrado conferenciante allín ${ }^{80}$. La Fundación nos dio una ayuda temporal para preparar una proposición para la continuación de tres años, empezando en marzo de 1940.

La parte más importante de la propuesta que escribimos entonces — desde el punto de vista de futuros desarrollos- fue el siguiente pasaje:

«Se propone - mediante la utilización de la técnica del panel desarrollado en los primeros dos años del proyecto- localizar a estos individuos que tienen que cambiar sus hábitos como respuesta a la secuencia continua de las emisiones; y estudiar después con detalle las circunstancias que rodean a la audiencia así como los cambios subsiguientes de estos individuos. El plan implica la selección de paneles básicamente comparables, pero de contraste, cada uno de ellos de alrededor de 200 personas, y el entrevistarlos seis u ocho veces a intervalos, a lo largo de una secuencia de un programa continuo que escuchasen».

Originalmente propuse que realizásemos nuestro test sobre «un programa del Departamento de Agricultura, ya que sus innovaciones produjeron grandes cambios en la conducta de los norteamericanos y, si esto era cierto, hay que afirmar que este Departamento ha desarrollado la utilización más extensiva de la radio en apoyo de sus políticas». No recuerdo el modo en que se alteró esta propuesta hasta el punto de que en noviembre de 1940 la elección se convirtió en el foco central del primer estudio de panel. Pero ese cambio se realizó y dio como resultado The People's Choice ${ }^{81}$. La tercera edición del libro (1968) contiene una introducción extensa que recoge el impacto de este primer estudio elaborado de una elección y el análisis político subsecuente aquí y fuera ${ }^{82}$.

Por lo que se refiere al trabajo y a la administración, el traslado a Columbia supuso muy poca diferencia. Nos colocaron en un edificio abandonado, que antes fue el lugar de la Facultad de Medicina, en la calle 52 y la avenida

${ }^{80}$ Un año más tarde fui nombrado miembro permanente del Departamento de Sociología. Esto hizo efectivo mi cambio clasificatorio desde la Psicología a la Sociología.

${ }^{81}$ Paul F. Lazarsfeld, Bernard Berelson y Hazel Gaudet, The People's Choice (Nueva York, 1944; 2. a y 3. a edición, Nueva York, 1948 y 1968).

${ }^{82}$ No teníamos suficientes fondos como para un panel de seiscientos entrevistados, y por eso solicitamos aportaciones adicionales. La más importante procedía de la revista Life mediante la intervención de Elmo Roper. Inmediatamente después de la elección de 1940, Life publicó dos gráficos basados en nuestras primeras tabulaciones. 
Amsterdam - una vecindad entonces conocida como "la cocina del infierno»- (Ahora forma parte de la zona del Centro Lincoln.) El eje financiero fue la ayuda de la Rockefeller, que se había renovado por tres años; a esto hay que añadir un gran número de contratos comerciales. A menudo los pagos se hacían con cheques personales a mi nombre, lo que después se distribuía como salarios de los directivos. Yo estaba más bien desinformado sobre las regulaciones de las «rentas internas» $\mathrm{y}$ - mirando atrás- me considero con suerte al no haber tenido problemas manejando dinero de este modo. El Centro tenía un equipo supervisor formado por cuatro profesores de Columbia y por Frank Stanton. Yendo por ese camino, la organización tomó el nombre actual: Bureau of Applied Social Research (Centro de Investigación Social Aplicada) ${ }^{83}$.

Por esa época, los Estados Unidos se prepararon y entraron finalmente en la guerra. En nuestro reducido mundo eso tuvo dos consecuencias. Stouffer entró como director de investigación en el ejército de los Estados Unidos, y utilizó el Centro y su personal para varios servicios. Los ingresos proporcionados por estas asignaciones fueron para el Centro y constituyeron una ayuda financiera importante. (Tuvimos un acuerdo similar con el Office of War Information [Centro de Información de la Guerra].) Robert Merton trabajó durante poco tiempo con Stouffer en Washington, y acabó volviendo a Nueva York y canalizando su trabajo a través del Bureau (Centro). Se mantuvo como director asociado y representó un papel crucial en su desarrollo posterior ${ }^{84}$. En nuestro trabajo del tiempo de la guerra nos concentramos en las pruebas de películas y radios que trataban de mantener la moral de algunos sectores de poblaciones civiles y militares. El registro principal de este esfuerzo se encuentra en el tercer volumen de The American Soldier, cuyos informes, entre otras muchas cosas, testifican la contribución al esfuerzo de la guerra del analizador de programas, un poco enmascarado, en la advertencia de Carl Hovland como editor y polígrafo del volumen ${ }^{85}$.

Hacia 1944 la necesidad de una organización más fuerte se hizo obvia. Columbia tenía un Consejo de investigación en ciencias sociales, y durante dos años recibimos de ellos una ayuda de 5.000 dólares; ellos asumieron probablemente también alguna supervisión financiera. Mi memoria sobre los detalles administrativos de este período de transición es tan confusa como fueron los acuerdos efectivos. Finalmente, el Consejo de Columbia — que hasta entonces

${ }^{83}$ El Centro empezó realmente al comienzo del proyecto de radio, y delebró su veinte aniversario en 1957.

${ }^{84}$ Sobre el origen de esta colaboración informó vívida y correctamente en un perfil sobre Merton publicado por M. M. HunT en el New Yorker (28 de enero de 1961). Mi colaboración con Merton en el Departamento de Sociología de Columbia trasciende el marco de este ensayo.

${ }^{85}$ Las publicaciones que se derivaron de este trabajo incluyen: Paul F. LAZARSFELD y Robert K. MERTON, "Studies in Radio and Film Propaganda», Transactions of the New York Academy of Sciences, 6 (1943), 58-79; Paul F. LAZARSFELD y Patricia L. Kendall, "The Listener Talks Back», en Radio and Health Education (Nueva York, 1945), 48-65; Robert K. MerTON y Patricia L. Kendall, «The Focussed Interview», American Journal of Sociology, 51 (1946), 541-557. 
sólo proporcionó pequeñas ayudas para los proyectos de los profesores- solicitó a su director (el economista Frederick Mills) que estudiase los esfuerzos investigadores de los diferentes Departamentos de la Facultad de Ciencia Política. Se envió un cuestionario; aparentemente, sólo el Departamento de Sociología informó de algunas actividades organizadas. De este modo, Mills recomendó al Consejo en agosto de 1944 lo siguiente:

"Que un comité especial del Consejo se creara para supervisar el Bureau of Applied Social Research y otras agencias del mismo tipo que pudieran operar bajo los auspicios del Consejo. Este comité de supervisión debe prestar particular atención durante el presente año académico a la evaluación del trabajo del Bureau, y a los medios mediante los cuales el trabajo de este Centro pudiera ser más efectivo si se relacionaba más efectivamente con otras actividades investigadoras de Columbia».

El comité así convocado era claramente consciente de que algo nuevo estaba teniendo lugar; pero estas recomendaciones positivas tenían más la naturaleza de una aquiescencia que de un liderazgo. En octubre de 1944 se plantearon una serie de recomendaciones, de las que las dos siguientes eran las más pertinentes para la existencia del Bureau:

«Se insistirá vivamente en la investigación y en la formación para ella. Dirigiendo el trabajo por contratos comerciales u otras organizaciones no será considerado como inconsistente con esta condición cuando se pruebe que el interés en la investigación se mantiene. Las contabilidades de las agencias que operen bajo la supervisión del Comité, sobre la administración de las agencias, deben establecerse y administrarse por el Bureau, a tenor de las provisiones propuestas por el Comité de patentes y el Comité de investigación social».

La gran innovación fue la decisión de que el trabajo contractual sería permitido. Hoy — cuando el $50 \%$ de los presupuestos que operan en Columbia proceden de contratos- esto no parece una revolución importante, pero señala — creo- el punto de cambio real en la historia de las Universidades norteamericanas. A pesar de ello, el comité omitió el punto principal que estábamos tratando de introducir. Nosotros no tratamos de hacer buena la expresión de Anatole France «buscar la libertad para dormir bajo los puentes del Sena»...: lo que queríamos era que Columbia aceptase el positivo deber de integrar en su programa de instrucción general la formación para la investigación social empírica ${ }^{86}$. Protestamos por el

${ }^{86}$ A lo largo del período del proyecto de Princeton el equipo de directivos se componía de empleados sin conexiones académicas. Los problemas eran muy simples: éstos querían salarios más altos y yo quería gastar más dinero en investigación. Cuando el Centro se mudó a Columbia se produjo lentamente un cambio. Cada vez más, los directivos eran graduados en el Departamento de Sociología para los que el estatus en la comunidad académica era importante. Obviamente, el comité 
fallo del comité al responder a esta posibilidad, y, como consecuencia, el Consejo estableció un comité especial para decidir el papel del Bureau dentro de la estructura de la Universidad. El presidente de este comité —importante para nosotros- fue Elliot Cleatham, profesor de ética legal en la Facultad de Derecho ${ }^{87}$; uno de sus miembros era Arthur MacMahon. El grupo se reunió frecuentemente entre diciembre de 1944 y mayo de 1945, y acabó recomendando el estatuto que el Bureau tiene hoy en día como "una unidad de investigación de la Facultad graduada de Ciencia Política de la Universidad de Columbia», con un espacio en el campus y un $10 \%$ de su presupuesto operativo proporcionado por la Universidad. Se ha conservado una enorme cantidad de la correspondencia y memorandos del comité de Cleatham, y espero que algún día pueda analizar los documentos con cuidado. Destaco — repasando los registros rápidamente- un memorando de quince páginas, escrito a Cleatham solicitando que describa la operación del Centro de investigación social de una manera que es bastante aplicable al Bureau como es en la actualidad y a todas las otras instituciones similares que desde entonces se han creado por todo el país. Una carta inicial mía a Cheatham visorea todos los temas a que nos enfrentábamos en esa época:

«Ha llegado a ser casi un lugar común que la Sociología se encuentra -en este momento- en un difícil momento de transición. Los estudiantes de este campo se dan cuenta de que la investigación empírica forma una parte integral de la Sociología, pero las Universidades no han desarrollado todavía presupuestos y provisiones de personal para este trabajo. Lo que se pudiera llamar un rezago institucional entre las necesidades de la disciplina y la institución administrativa aparece en prácticamente todas las Universidades. Los problemas administrativos de los que es responsable su Comité en este momento se pueden entender se derivan de la anomalía de tener una división de la Universidad que es esencialmente automantenida».

\section{Yo en esa situación ofrecí un modo diferente de resolver este problema:}

"Yo podía haber gastado todas mis energías en promover la idea de que la administración de la Universidad debería proporcionar el necesa-

había sido informado de este aspecto de la relación Bureau-Departamento universitario. Su informe establecía que sería necesario para «las regulaciones-marco relativas a la contratación de miembros directivos de las agencias de investigación y para las responsabilidades de la Universidad hacia esas agencias». La cuestión sólo se zanjó después de al menos tres sesiones. Concernía a la administración principalmente el problema de los contratos; luché sobre todo por el reconocimiento y financiación hechos por la Universidad; los directivos no insistieron demasiado porque eran una nueva casta y se les demandaba mucho por todas las Universidades principales. Para los directivos de hoy, los problemas de estatus y estabilidad laboral son tema de la prioridad más alta.

${ }^{87}$ Cheatham era un directivo que trabajaba fuerte, muy efectivo e intuitivo. Enseñé una de sus cartas - fechada el 1 de febrero de 1945- a Robert Lynd. Me contestó con la siguiente anotación a lápiz: «una carta toda ella admirable procedente de un hombre civilizado y humano que conlleva su propio super-ego». 
rio presupuesto mínimo de 25.000 dólares para establecer un laboratorio de investigación social. Si hubiera tenido éxito este laboratorio se debería establecer como una parte integral de la Universidad desde el principio, y su trabajo debería proceder de un modo académico, conocido».

No creía entonces, no lo creo ahora, que hubiera la menor oportunidad de que esto resultara así. Como si yo supiera que alguna vez iba a escribir la presente memoria, anoté el registro de mi estrategia y mi confianza:

«Pero como yo era demasiado impaciente o demasiado pesimista, o demasiado agudamente consciente del modo en que se desarrollan las instituciones, tomé un camino diferente. El actual Bureau se levantó sobre una ayuda original de la Rockefeller, sin ayuda presupuestaria de la Universidad. Trabajos de servicios para agencias comerciales y gubernamentales fueron las principales fuentes de ingresos. Prácticamente todos estos estudios tenían aspectos valiosos científicamente, pero sólo tiempo y dinero supletorio se dedicó a fines exclusivamente científicos. No obstante, el Bureau existe ahora como laboratorio de ciencia social y está a la completa disposición del Departamento».

Entonces jugué en el tablero mi saque final. ¿Puede una Universidad moderna hacer algo sin un Centro semejante a nuestro Bureau? Si no, ¿pude yo tener una oportunidad para algo muy próximo al chantaje? Lo intenté siguiendo la siguiente línea:

Tal vez la operación poco ortodoxa del Bureau crea problemas con sus ventajas y sus desventajas. Me parece perfectamente legítimo considerar el modo de haberlo hecho mejor, cerrando, y esperando hasta un tiempo de madurez para esta operación, lo que se traduciría en un completo apoyo económico de la Universidad. Si — por otra parte- se está de acuerdo en que las nuevas instituciones se crean a menudo primero y después se legalizan, el trabajo de su Comité pudiera parecer como parte de este proceso.

La carta se escribió en enero de 1945. Veintitrés años después me encuentro con que soy presidente de un Consejo de dieciséis representantes distinguidos de las Escuelas y Departamentos graduados de Columbia —un Consejo que el Comité de Cheatham, cuando legitimó al Bureau, estableció una estrecha vigilancia de su peligroso director-. Sería estupendo si ello simbolizase la victoria final de una idea nacida en Viena casi hace medio siglo. Pero no es así. Las calificaciones de esos bureaus existen a lo largo de todo el país, muchas de ellas dirigidas por alumnos del prototipo de Columbia, pero realmente todavía no están integradas en la estructura de las Universidades. El esfuerzo continúa. Este año he llevado a la administración de Columbia a establecer un nuevo comité para ver si la posición de nuestro Bureau se puede mejorar. Para poner al corriente a los miembros de este comité les repartí copias de la carta que acabo de citar. 


\section{APÉNDICE}

\section{El Instituto de Investigación Social en la Universidad norteamericana*}

Todos ustedes son conscientes de las controversias que han surgido en torno a estos Institutos. En la cara positiva se pueden anotar las siguientes: los Institutos proporcionan formación técnica a los estudiantes graduados que se orientan hacia lo empírico; los proyectos ofrecen a los estudiantes oportunidades para tener un contexto más cercano con sociólogos reconocidos; el recoger datos para fines prácticos proporciona materiales para tesis universitarias mediante estudios más detallados, o lo que a veces se llama análisis secundario; los miembros de un Departamento con un instituto efectivo pueden proporcionar sustancia para las clases con un envidiable aporte de datos actuales; se desarrollan las capacidades de la cooperación intelectual y la división del trabajo; se ofrecen oportunidades para los sociólogos más jóvenes en sus primeras publicaciones.

La otra cara, la del debate, donde el argumento marcha del siguiente modo: los estudiantes que reciben la mayor parte de su formación en proyectos organizados se convierten en partidistas de ese proyecto; en lugar de desarrollar intereses por sí mismos, se convierten en mercenarios de sus empleadores; donde los Institutos llegan a ser influyentes, los problemas sociológicos importantes se desatienden porque no llevan por sí mismos al estudio de la «maquinaria de investigación»; las personas que trabajan mejor por sí mismas se encuentran sin apoyo y son miradas como outsiders.

La situación, pues, es prometedora pero confusa. Permitimos que estos Institutos se desarrollen sin ofrecerles un apoyo permanente, sin integrarlos en la estructura general de la Universidad, sin ni siquiera conocer realmente lo que está pasando fuera de nuestro inmediato entorno académico. Como mínimo resulta imperativo que se realice un estudio más detallado de la situación actual. Esto llevaría esperanzadamente a recomendaciones para los directivos de las Universidades, para miembros de nuestra propia asociación, y todos los otros responsables del problema básico del modo en que hay que encajar la avalancha de investigación social empírica dentro de las actividades educativas del momento presente, evitando improvisaciones institucionales poco cuidadosas que destruyen los valores tradicionales o impiden los nuevos desarrollos creativos. Es cierto que no tenemos ninguna fórmula perfecta para los Institutos que se incorporan en nuestra educación graduada. Pero el pluralismo no es lo mismo que la anarquía, y es anarquía a lo que nos estamos enfrentando en este momento. Alguna forma de apoyo fuerte permanente, asimilación de posiciones en enseñanza e Institutos de investigación, una mejor división planeada del tiempo de los estudiantes entre clases y proyecto de investigación, una supervisión más estrecha de las actividades de los Institutos por inspectores

* Se reimprime con permiso de la American Sociological Review, 27 (1962), 763-765. 
educativos, más inyección explícita de la teoría social en el trabajo de los Institutos - todo esto espera un debate sistemático y un documento que pueda realizar el servicio que el informe Flexner proporcionó a la educación médica hace cincuenta años.

En un informe de ese tipo el papel del director del Instituto tendrá que figurar de modo prominente. Déjenme situarlo en un marco de referencia más amplio. Estamos confrontados hoy en día —en nuestras Universidades- con un problema serio que puede ser clasificado como "vacío de poder académico». Cuando empezó la educación graduada en este país nadie dudaba que el presidente (o rector) de la Universidad era una figura importante. Gilman en John Hopkins y White en Cornell eran intelectuales tanto como líderes de gobierno. Stanley Hall en Clark era impresionante como presidente y como psicólogo. Inversamente, los profesores individuales estaban profundamente implicados en la innovación organizativa. John W. Burges forzó la creación de un profesorado graduado (con títulos universitarios superiores) ante los consejeros de Columbia. En su autobiografía describe ágilmente lo que esto quería decir para él como profesor y como académico (o «escolar»). Silliman sacrificó su fortuna privada para establecer un laboratorio de física en su casa y, finalmente, convenció a los consejeros de Yale de que las ciencias naturales no eran una amenaza espiritual para los jóvenes norteamericanos.

Sin embargo, hoy en día observamos una peligrosa divergencia: la libertad académica es cada vez más interpretada de tal manera que significa que hay que mantener la administración (o gobierno) aparte de los asuntos académicos; y los profesores, a su vez, han llegado a considerar a la administración como algo por debajo de su dignidad. Pero las innovaciones educativas son por definición tareas tan intelectuales como administrativas. Y así éstas son «tierra de nadie»: el presidente y equipo de gobierno esperan que los profesores tomen la iniciativa; los profesores, por su parte, consideran que esas cuestiones consumen tiempo de sus trabajos verdaderamente escolares. En consecuencia, muchas de nuestras Universidades tienen un bajo nivel peligroso de desarrollo institucional.

La consecuencia institucional de los Institutos de Investigación consiste en que los hombres formados, inevitablemente son capaces y están deseosos de combinar el liderazgo intelectual y administrativo. Un director de Instituto —incluso si su unidad sólo facilita investigación de profesores - tiene que entrenar un equipo directivo capaz de aconsejar sobre funciones importantes de la investigación. No resulta imposible que —sobre temas específicos- la experiencia colectiva del equipo directivo del Instituto sobrepase las capacidades de los miembros individuales del profesorado. El que ha vivido con los resultados de los cuestionarios puede ayudar a escribir un mejor cuestionario sobre un objeto en el que no es experto. El que es capaz de desenterrar documentos y fuentes de datos sobre muchos temas aporta una eficiencia mayor incluso sobre un objeto que previamente no había tratado. En una unidad autónoma ello está incluso más acentuado. Aquí el grupo directivo realiza 
como propia una agenda de trabajo. Se necesita una jerarquía, desde asistentes (o ayudantes) hasta supervisores de proyecto, hasta el director de un proyecto $\mathrm{y}$, finalmente, hasta el mismo director. Este último es al menos responsable de los informes y publicaciones. Pero también al director le incumbe el mantenimiento de lo que se llama a veces la «imagen» de su operación. Su prestigio, su atracción para directivos y estudiantes, y su atractivo para conseguir los fondos son autogenerados, no derivan sólo de la reputación de los Departamentos de enseñanzas. El equipo profesional ve su futura carrera estrechamente ligada al destino de la unidad — un hecho que a veces produce problemas desafiantes en organizaciones humanas.

Al mismo tiempo, el director tiene que desarrollar las capacidades de coordinación tan necesarias en una Universidad moderna. A menudo el puesto de esta unidad en el organigrama no está bien definido. La novedad de toda la idea produce inestabilidad y exige considerable creatividad institucional. Y, por último, tenemos francamente que encararnos con el hecho de que en nuestro sistema de educación superior el encaje de los fondos del presupuesto con intereses sustantivos intelectuales es una característica y un problema que perdura. El director del Instituto conoce las capacidades e intereses de los profesores miembros, y él pone juntos hombres y dineros. Como rol o papel no está malamente descrito como el papel del «bolsista de las ideas». A veces tiene que trabajar duro para obtener fondos para una más que extravagante idea de investigación que le ha sido sugerida; en otras ocasiones una ayuda posible parece muy atractiva y él tratará de descubrir —entre algunos de sus colegas profesores - lo que se podría llamar diplomáticamente un «interés latente».

Me temo que no es éste el foro apropiado para reformar a los rectores de las Universidades. Pero puedo al menos tratar de convencer a algunos de ustedes de que dirigir un instituto de investigación no está más reñido con el trabajo escolar que lo está enseñar. El director se enfrenta con algunos problemas de investigación que le permiten mostrar sus gustos y capacidades intelectuales, mientras el profesor individual pudiera encontrarse conminado a estudiar cosas prematuramente. La multitud de datos que pasan por las manos del director amplía considerablemente su experiencia. Las conferencias con directivos proporcionan una única y sólida mesa de nuevas ideas. Incluso si las negociaciones para ayudas abren los ojos a otros mundos que un sociólogo puede convertir en gran ventaja en su propio trabajo. Indudablemente, no todo tipo de personalidad está preparado para su papel, e incluso el tipo correcto de hombre necesita entrenamiento adecuado. Pero son considerables las oportunidades para la autoexpresión y para el crecimiento intelectual, y los sociólogos (en particular) no deben equivocarse por el estereotipo prevaleciente de administración. 


\section{CRÍTICA DE LIBROS}

